
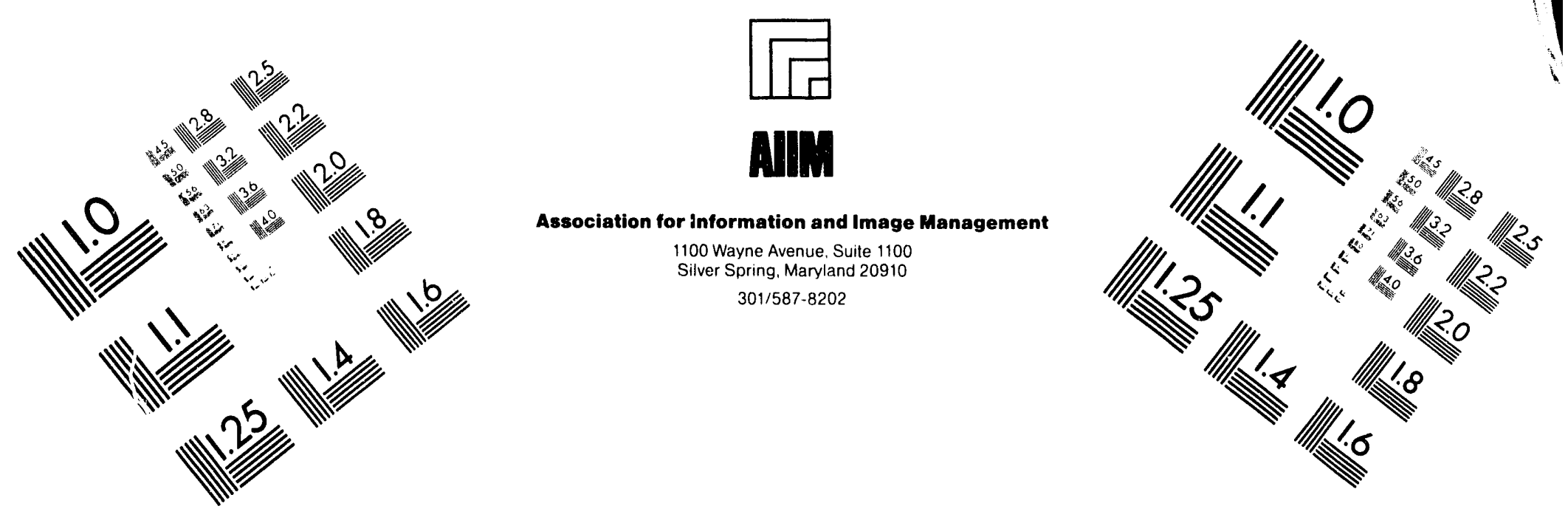

\title{
Centimeter
}

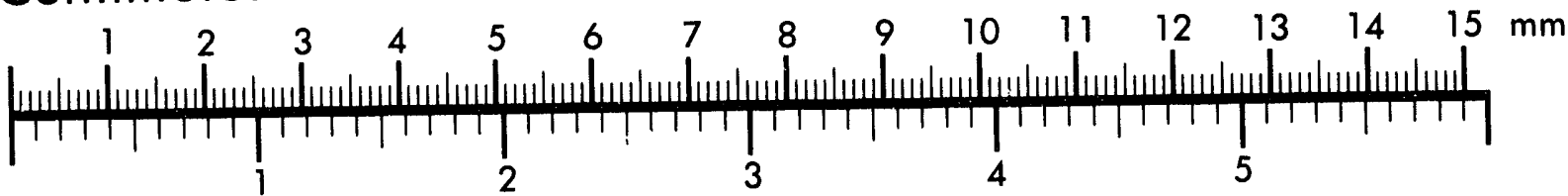
Inches
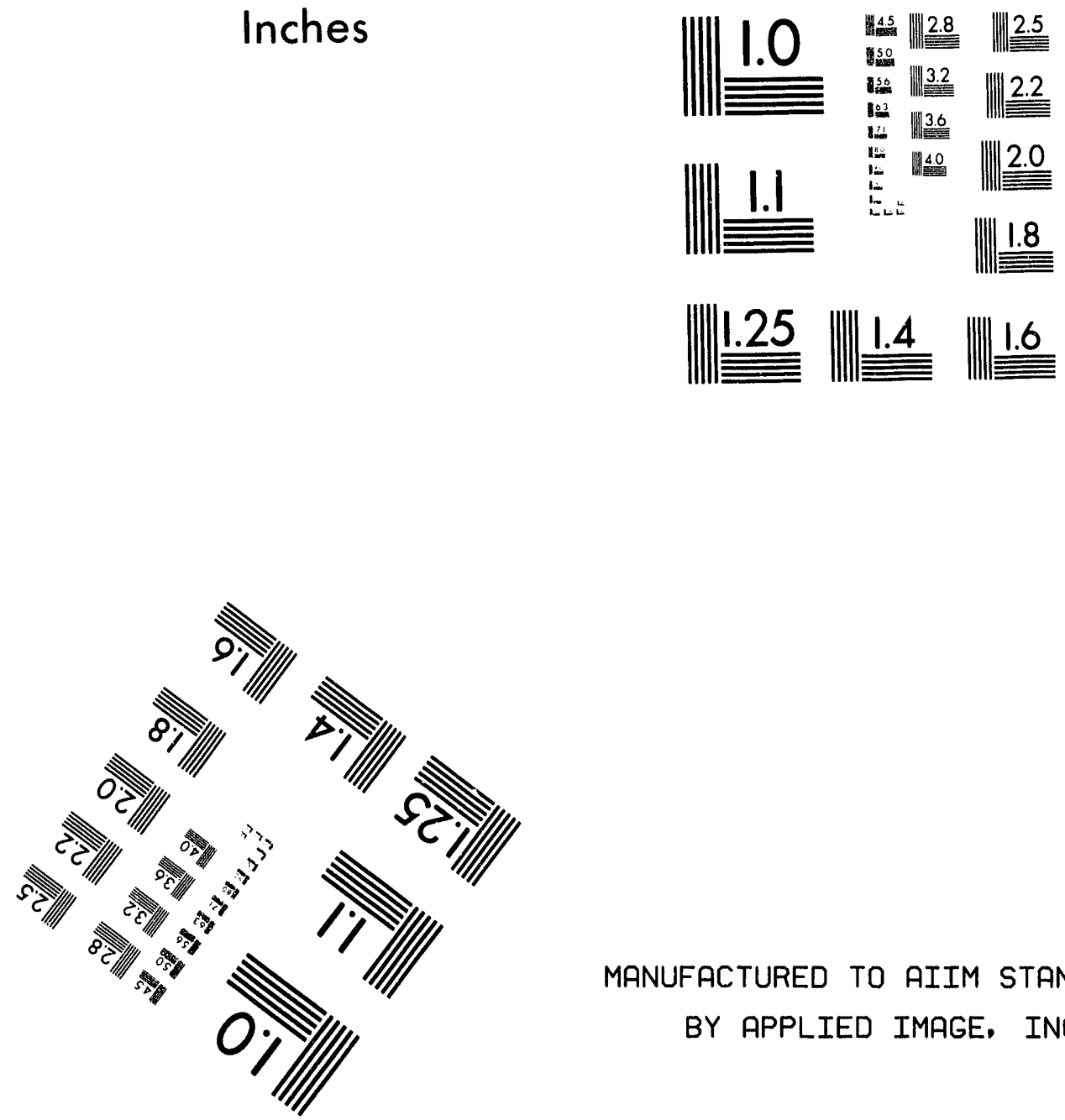

MANUFACTURED TO AIIM STANDARDS

BY APPLIED IMAGE, INC.

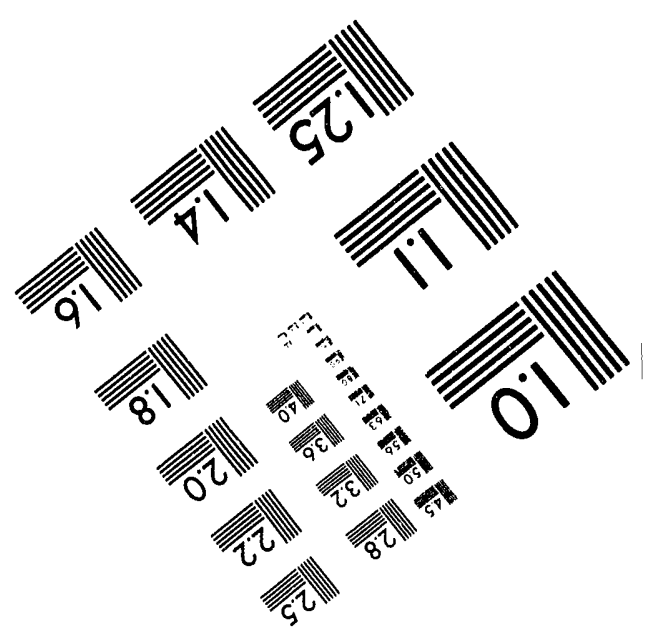



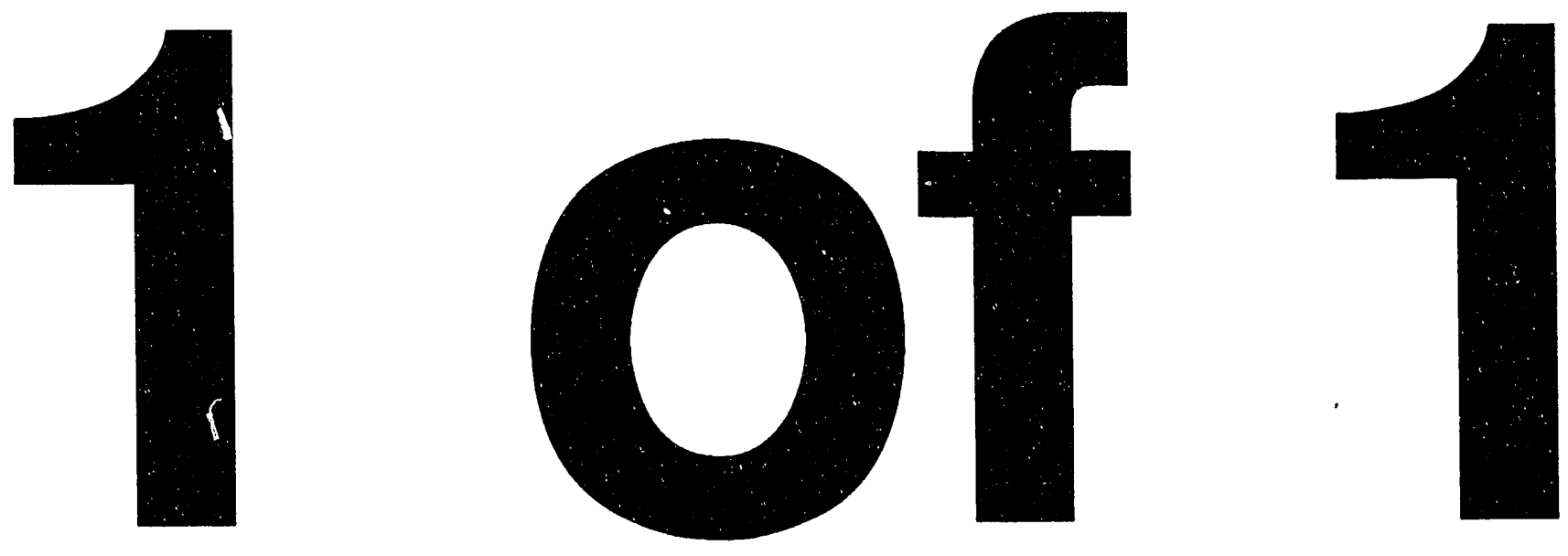


\section{A Review of Wind Field Models for Atmospheric Transport}

Hanford Environmental Dose

Reconstruction Project

J. V. Ramsdell, Jr.

E. D. Skyllingstad

June 1993

Letter report prepared for the Technical Steering Panel and the Centers for Disease Control and Prevention under Contract 200-92-0503 (CDC)/18620 (BNW)

\section{Battelle}

Pacific Northwest Laboratories

Richland, Washington 99352 


\section{Preface}

The Hanford Environmental Dose Reconstruction (HEDR) Project was prompted by mounting concern about possible health effects to the public from more than $\mathbf{4 0}$ years of nuclear operations at the Hanford Site near Richland, Washington. The primary objective of the HEDR Project is to estimate the radiation dose (with descriptions of the uncertainties inherent in such estimates) that individuals could have received as a result of radionuclide emissions since 1944 from the U.S. Department of Energy's (DOE) Hanford Site. An independent Technical Steering Panel (TSP) directs the work on the project which is conducted by Battelle, Pacific Northwest Laboratories (BNW) under contract with the Centers for Disease Control and Prevention.

The HEDR Project work includes a number of technical and administrative tasks. This report is a product of the technical task that is estimating the transport, diffusion, and deposition of radionuclides released to the atmosphere. The report describes methods used to transform observed wind data into wind fields. The wind fields are prepared in the Regional Atmospheric Transport Code for Hanford Emission Tracking (RATCHET) and are used to determine transport by radionuclides after their release into the atmosphere.

Wind fields play an essential role in the process of estimating the air concentrations and surface contamination at specific locations in the vicinity of Hanford. Othei tasks within the HEDR Project use the air concentrations and surface contamination computed by RATCHET in calculating doses.

This report fulfills HEDR Project Milestone 0402A. 


\section{Summary}

The primary objective of the Hanford Environmental Dose Reconstruction (HEDR) Project is to estimate the radiation dose that individuals could have received as a result of emissions since 1944 from the U.S. Department of Energy's (DOE) Hanford Site near Richland, Washington.

The HEDR Project is developing a computer code to estimate these doses and their uncertainties. The code, known as the HEDR Integrated Code (HEDRIC), consists of four separate component codes. One of the component codes, called the Regional Atmospheric Transport Code for Hanford Emission Tracking (RATCHET) combines meteorological and release data to estimate time-integrated air concenirations and surface contamination at specific locations in the vicinity of the Hanford Site. The RATCHET domain covers approximately 75,000 square miles, extending from the crest of the Cascade Mountains on the west to the eastern edge of the Idaho panhandle and from central Oregon on the south to the Canadian border. This letter report explains the procedures in RATCHET that transform observed wind data into the wind fields used in atmospheric transport calculations. It also describes and evaluates alternative procedures not selected for use in RATCHET.

The initial version of RATCHET uses surface $(\sim 10 \mathrm{~m})$ wind observation data and a simple weighted interpolation method to generate wind fields. Atmospheric transport calculations are made using winds from these fields extrapolated to the effective release height, generally between 61 and $100 \mathrm{~m}$ above ground. The extrapolation is done with a wind profile model that adjusts wind speed for changes in height but does not adjust wind direction. The 100-meter level wind speed is used for transport calculations if the release height is greater than $100 \mathrm{~m}$.

Methods for interpolating and extrapolating observed winds to generate initial wind field estimates are described in the report, as are methods of adjusting the initial estimates. Based on evaluation of these methods for applicability to the HEDR Project, the following decisions were made:

- continue to use the initial, interpolated wind fields for transport calculations

- use the wind from the 200-foot level of the Hanford Meteorological Station (HMS) tower in wind field interpolation

- change the limitation on application of the wind profile during stable atmospheric conditions.

Alternatives considered, but not selected, include:

- adjusting initial wind field estimates to obtain mass consistency

- estimating upper-level winds from surface meteorological data (upper-level wind data are not available for the period of interest). 
No experimental evidence indicates that either of these alternatives would improve the ability of RATCHET to estimate the transport of radionuclides released to the atmosphere from Hanford operations. 


\section{Glossary}

Acronym/Term

AFB

$\mathrm{B}$ and $\mathrm{T}$

BNW

Cartesian

CDC

CIDER

Coriolis force

DESCARTES

DOE

Ekman spiral

Froude number

FY

HEDR

HEDRIC

HMS

Monin-Obukhov length

Monte Carlo

\section{Definition}

Air Force Base

Separation plant designations

Battelle, Pacific Northwest Laboratories

Refers to a coordinate system in which positions are expressed by distances from the axes, as opposed to polar and spherical coordinates, which use angles as well as distances.

Centers for Disease Control and Prevention

Calculations of Individual Doses from Environmental Radionuclides

An apparent force, due to the earth's rotation, that causes moving air to deviate to the right in the northern hemisphere

Dynamic EStimates of Concentrations And Radionuclides in Terrestrial EnvironmentS

Department of Energy

Theoretical variation of wind speed and direction with height under a very restrictive set of assumptions

A nondimensional number expressing the ratio between inertial and gravitational forces

Fiscal year

Hanford Environmental Dose Reconstruction

HEDR Integrated Code

Hanford Meteorological Station

A scaling length for atmospheric turbulence in the surface layer defined by the heat flux and a scaling velocity called the friction velocity

A mathematical method of estimating output distributions when model input is uncertain 
NOABL

NUREG/CR

PST

RATCHET

STRM

TSP
A wind field interpolation model that includes mass-consistent adjustment of the vertical field

Nuclear Regulatory Commission.Contractor Report

Pacific Standard Time

Regional Atmospheric Transport Code for Hanford Emission Tracking

Source Term Release Model

Technical Steering Panel 


\section{Contents}

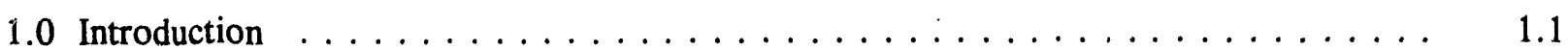

1.1 Overview of the HEDR Integrated Code $\ldots \ldots \ldots \ldots \ldots \ldots \ldots$

1.2 Model Domain and Wind Data $\ldots \ldots \ldots \ldots \ldots \ldots \ldots$

1.3 Wind Field Estimation $\ldots \ldots \ldots \ldots \ldots \ldots \ldots \ldots \ldots$

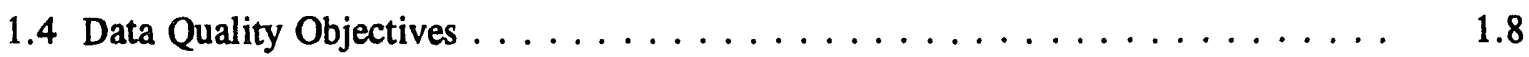

1.4 .1 Accuracy $\ldots \ldots \ldots \ldots \ldots \ldots \ldots \ldots \ldots \ldots \ldots \ldots$

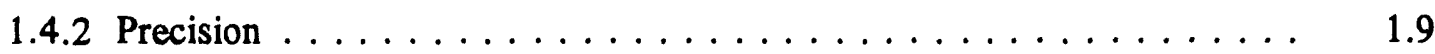

1.4 .3 Completeness $\ldots \ldots \ldots \ldots \ldots \ldots \ldots \ldots \ldots \ldots \ldots \ldots$

1.4.4 Representativeness . . . . . . . . . . . . . . . . . . 1.9

1.4.5 Comparability . . . . . . . . . . . . . . . . 1.10

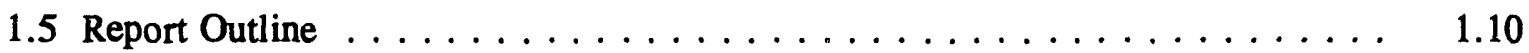

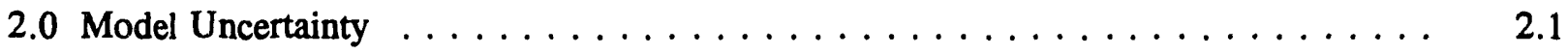

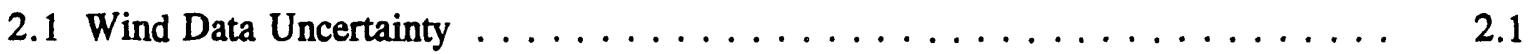

2.2 Hourly Release Rate Uncertainty . . . . . . . . . . . . . . 2.3

2.3 Preliminary Estimates of Model Output Variability . . . . . . . . . . . . 2.4

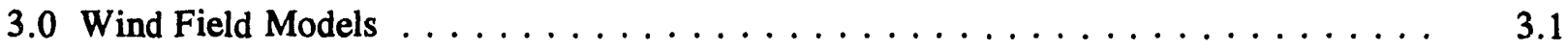

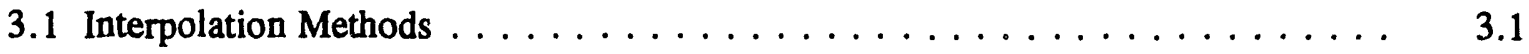

3.1.1 Vertical Interpolation of Winds $\ldots \ldots \ldots \ldots \ldots \ldots \ldots \ldots \ldots$

3.1.2 Horizontal interpolation of Winds $\ldots \ldots \ldots \ldots \ldots \ldots \ldots$

3.2 Adjustment Techniques $\ldots \ldots \ldots \ldots \ldots \ldots \ldots \ldots \ldots \ldots \ldots$

4.0 RATCHET Wind Field Model $\ldots \ldots \ldots \ldots \ldots \ldots \ldots \ldots \ldots \ldots \ldots \ldots$

4.1 Vertical Extrapolation of Winds $\ldots \ldots \ldots \ldots \ldots \ldots \ldots \ldots \ldots$ 
4.2 Profile Model Limitations $\ldots \ldots \ldots \ldots \ldots \ldots \ldots \ldots \ldots \ldots$

4.3 Wind Direction Shear $\ldots \ldots \ldots \ldots \ldots \ldots \ldots \ldots \ldots \ldots \ldots$

4.3.1 Rotation of the Surface Wind Direction . . . . . . . . . 4.2

4.3.2 Geostrophic Wind from Pressure Data . . . . . . . . . . . 4.4

4.3.3 Estimating Direction Shear from HMS Tower Data . . . . . . . . . . 4.6

4.4 Horizontal Interpolation of Winds $\ldots \ldots \ldots \ldots \ldots \ldots \ldots$

4.5 Wind Field Adjustments $\ldots \ldots \ldots \ldots \ldots \ldots \ldots \ldots \ldots . \ldots \ldots$

5.0 Conclusions $\ldots \ldots \ldots \ldots \ldots \ldots \ldots \ldots \ldots \ldots \ldots \ldots \ldots \ldots \ldots \ldots$

5.1 Uncertainty in Model Input and Variability in Model Output . . . . . . . . 5.1

5.2 Boundary Layer Wind Profile $\ldots \ldots \ldots \ldots \ldots \ldots \ldots \ldots \ldots \ldots \ldots \ldots$

5.3 Wind Direction Shear $\ldots \ldots \ldots \ldots \ldots \ldots \ldots \ldots \ldots \ldots \ldots \ldots$

5.4 Horizontal Interpolation $\ldots \ldots \ldots \ldots \ldots \ldots \ldots \ldots \ldots \ldots \ldots$

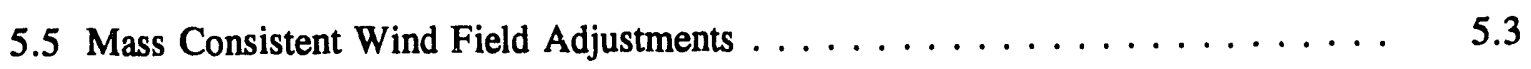

5.6 RATCHET Status $\ldots \ldots \ldots \ldots \ldots \ldots \ldots \ldots \ldots \ldots \ldots \ldots \ldots$

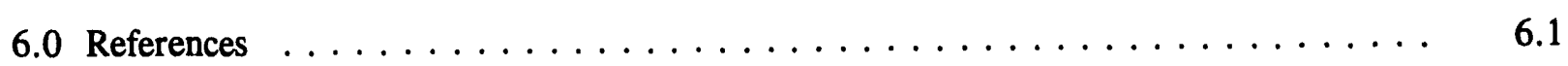




\section{Figures}

1.1 Component Interactions - HEDR Integrated Code $\ldots \ldots \ldots \ldots \ldots$

1.2 RATCHET Procedure to Prepare Wind Fields/Move Puffs $\ldots \ldots \ldots \ldots \ldots$

1.3 Meteorological Stations Within the HEDR Atmospheric Model Domain . . . . . . . 1.4

1.4 Topography of the HEDR Atmospheric Model Domain $\ldots \ldots \ldots \ldots \ldots$

1.5 Typical Surface-Layer Wind Speed Profile $\ldots \ldots \ldots \ldots \ldots \ldots$

1.6 Weighting Functions Used in Wind Component Interpolation at a Reference

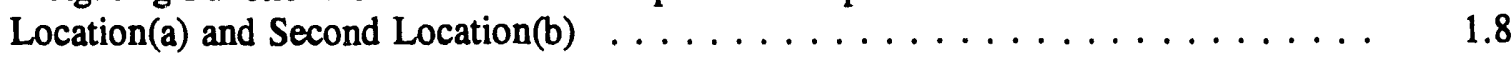

2.1 Frequency of Wind Direction Shifts at the HMS Tower $\ldots \ldots \ldots \ldots$

2.2 Standard Deviation of Wind Direction Differences as a Function of Time Lag . . . $\quad 2.4$

2.3 Cumulative Frequency of Wind Direction Differences for Observations Separated

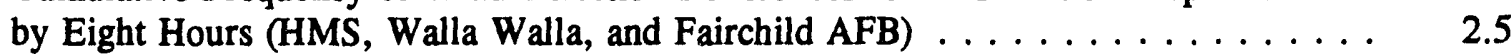

2.4 Frequency of Consecutive Wind Direction Observations in a Common Sector (HMS, Walla Walla, and Fairchild AFB) $\ldots \ldots \ldots \ldots \ldots$

2.5 Named Node Locations - HEDR Atmospheric Model Domain . . . . . . . . . 2.7

2.6 Geographical Pattern of Median Iodine-131 Time-Integrated Air Concentrations

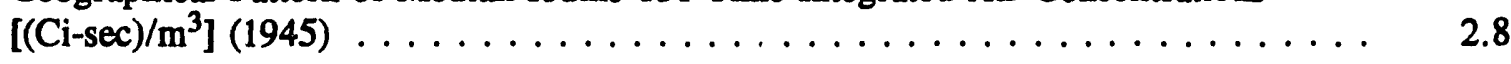

3.1 Interpolation Variations for Three Weighting Schemes $\ldots \ldots \ldots \ldots \ldots \ldots$

3.2 Comparison of Wind Fields Using Two Weighting Schemes $\ldots \ldots \ldots \ldots$

3.3 NOABL Adjustments to Estimated Wind Fields $\ldots \ldots \ldots \ldots \ldots$

4.1 Frequency of Wind Direction Differences Between Two HMS Tower Levels . . . . . 4.3

\section{Tables}

2.1 Time-Integrated Air Concentrations $\left[(\mathrm{Ci}-\mathrm{sec}) / \mathrm{m}^{3}\right](1945) \ldots \ldots \ldots \ldots$ 


\subsection{Introduction}

This letter report describes and evaluates procedures for transforming observed wind data into wind fields used in the atmospheric transport modeling for the Hanford Environmental Dose Reconstruction (HEDR) Project.

The introduction provides an overview of the computer model used for HEDR dose estimates, briefly describes the atmospheric model domain and the wind data available for use in generating wind fields, and outlines the process of transforming observed wind data to wind fields. Data quality objectives set for the atmospheric modeling task within the HEDR Project are discussed. In addition, this section presents an outline of the remainder of the report.

\subsection{Overview of the HEDR Integrated Code}

The HEDR Project is developing an integrated computer code for estimating radiation doses and their uncertainties. This code, called the HEDR Integrated Code (HEDRIC) consists of four separate components (Ikenberry et al. 1992). The interactions of these components are shown in Figure 1.1. The first component of HEDRIC is the Source Term Release Model (STRM) (Heeb 1993). The STRM code uses information on the operation of Hanford reactors and chemical processing plants to estimate hourly releases of radionuclides from the chemical processing plant stacks. The second HEDRIC component is the Regional Atmospheric Transport Code for Hanford Emission Tracking (RATCHET). The RATCHET code combines the radionuclide release information produced by STRM with observed meteorological data and calculates daily time-integrated air concentrations and surface contamination throughout the HEDR model domain (Ramsdell and Burk 1992). The two remaining components in HEDRIC, Dynamic EStimates of Concentrations And Radionuclides in Terrestrial EnvironmentS (DESCARTES) and Calculations of Individual Doses from Environmental Radionuclides (CIDER), use the time-integrated air concentrations and surface contamination to compute annual doses (Ikenberry et al. 1992).

This report focuses on RATCHET. Spacifically, it describes procedures for estimating wind fields from observed (measured) wind data. Wind fields are used to calculate the transport of radionuclides released to the air from Hanford operations. Figure 1.2 shows the process that occurs within the RATCHET code. Observed wind data are used to generate wind fields. These fields are then used to move the puffs containing radionuclides within the model domain. Ultimately, the radionuclide concentrations in puffs are used to calculate time-integrated air concentrations and surface contamination at specific locations. Thus, wind fields are key elements in this process.

\subsection{Model Domain and Wind Data}

The intended use of the RATCHET code is to calculate daily time-integrated air concentrations and surface contamination in eastern Washington, northeastern Oregon, and northern Idaho for the period from December 1944 through 1949. The atmospheric model domain (shown in Figure 1.3) 


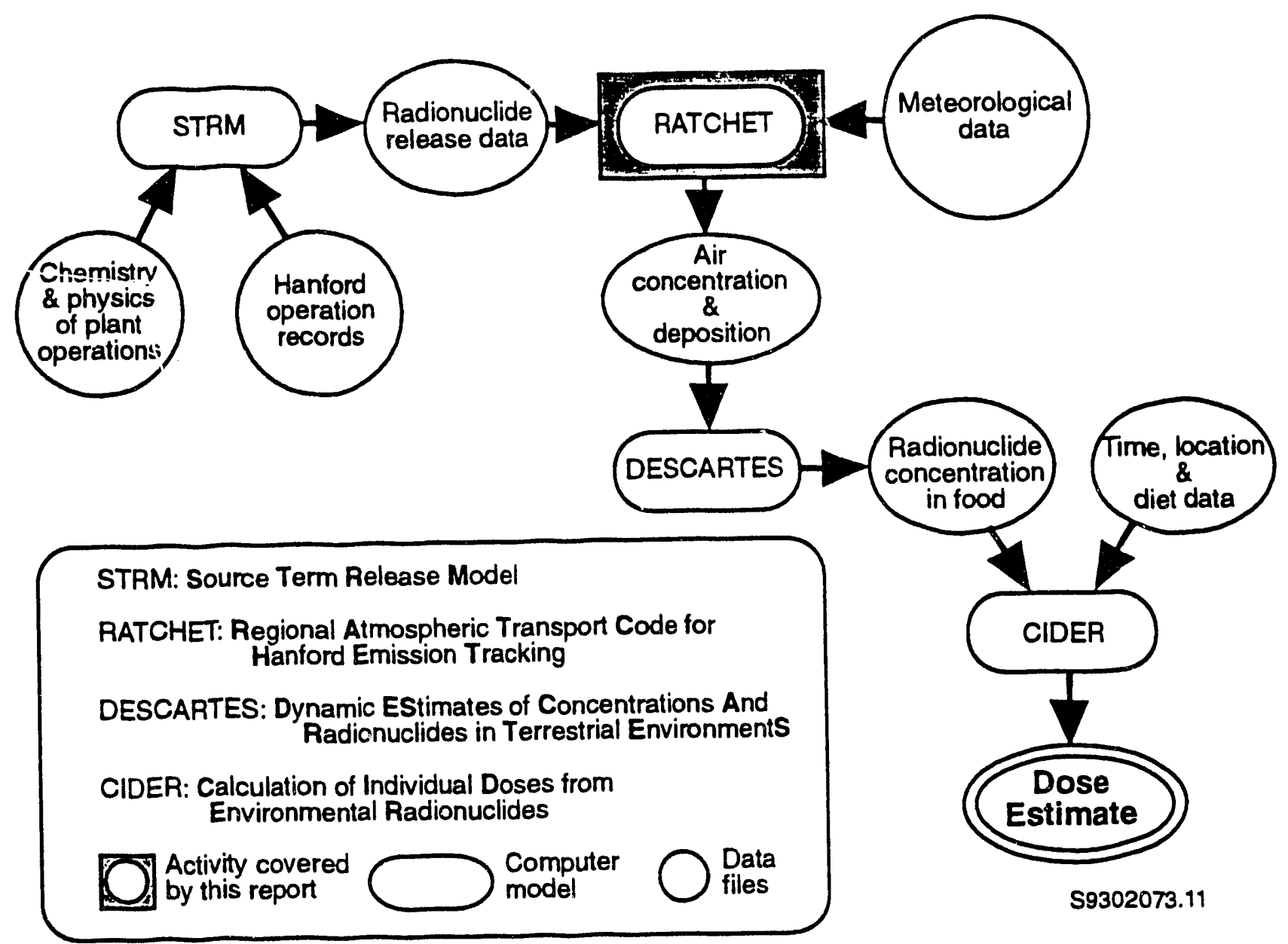

Figure 1.1. Compcnent Interactions - HEDR Integrated Code

covers approximately 194,000 square kilometers (75,000 square miles). The domain is a rectangle centered at $46^{\circ} 40^{\prime} \mathrm{N}, 118^{\circ} 45^{\circ} \mathrm{W}$. The Hanford Site, shown by the hatched area, is slightly west of the center of the domain. Distances within the domain can be estimated using the tick marks on the domain border. These marks are spaced at 12-mile intervals.

The meteorological records available for the HEDR study period are described by Stage et al. (1993). These records contain data from surface meteorological observations. The Hanford Meteorological Station (HMS) meteorological data are available for the Hanford Plants and 24 other locations in and adjacent to the HEDR atmospheric model domain. Figure 1.3 shows these locations. However, data are not available for all of the locations for the full period under consideration. Typically, only 10 to 15 locations have meteorological data at any given time.

Atmospheric dispersion models frequently use wind and temperature data obtained with balloonborne instruments, referred to as upper-air data. Unfortunately, no upper-air data are available for 


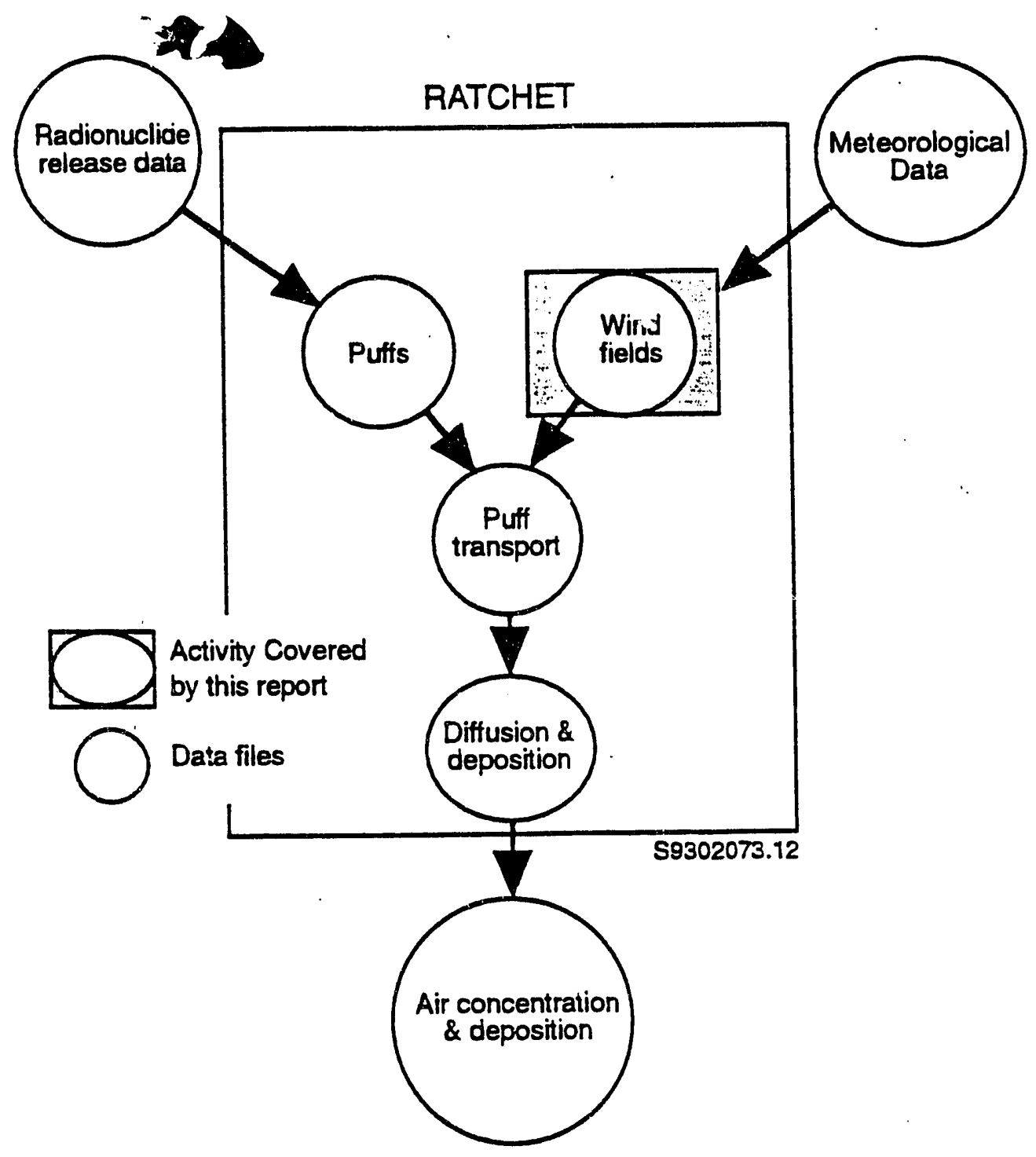

Figure 1.2. RATCHET Procedure to Prepare Wind Fields/Move Puffs

the mid-1940s for the HEDR atmospheric model domain. The first measurements of this type were not made until the late 1940s, well after the period of the maximum releases to the atmosphere. As a result, the atmospheric transport and dispersion estimates for the HEDR Project must be based on surface meteorological data.

From 1944 through 1949, meteorological observations were made and recorded at hourly intervals on the half hour. Wind speed observations were made by an observer watching a dial for a 1 -minute period and recording an estimate of the average speed in knots. Wind direction observations were made by watching lights on a compass dial and recording the direction in one of 16 compass points $\left(22.5^{\circ}\right.$ wide secto $\left.s\right)$. Hanford wind records are an exception to the general rule. Hourly 


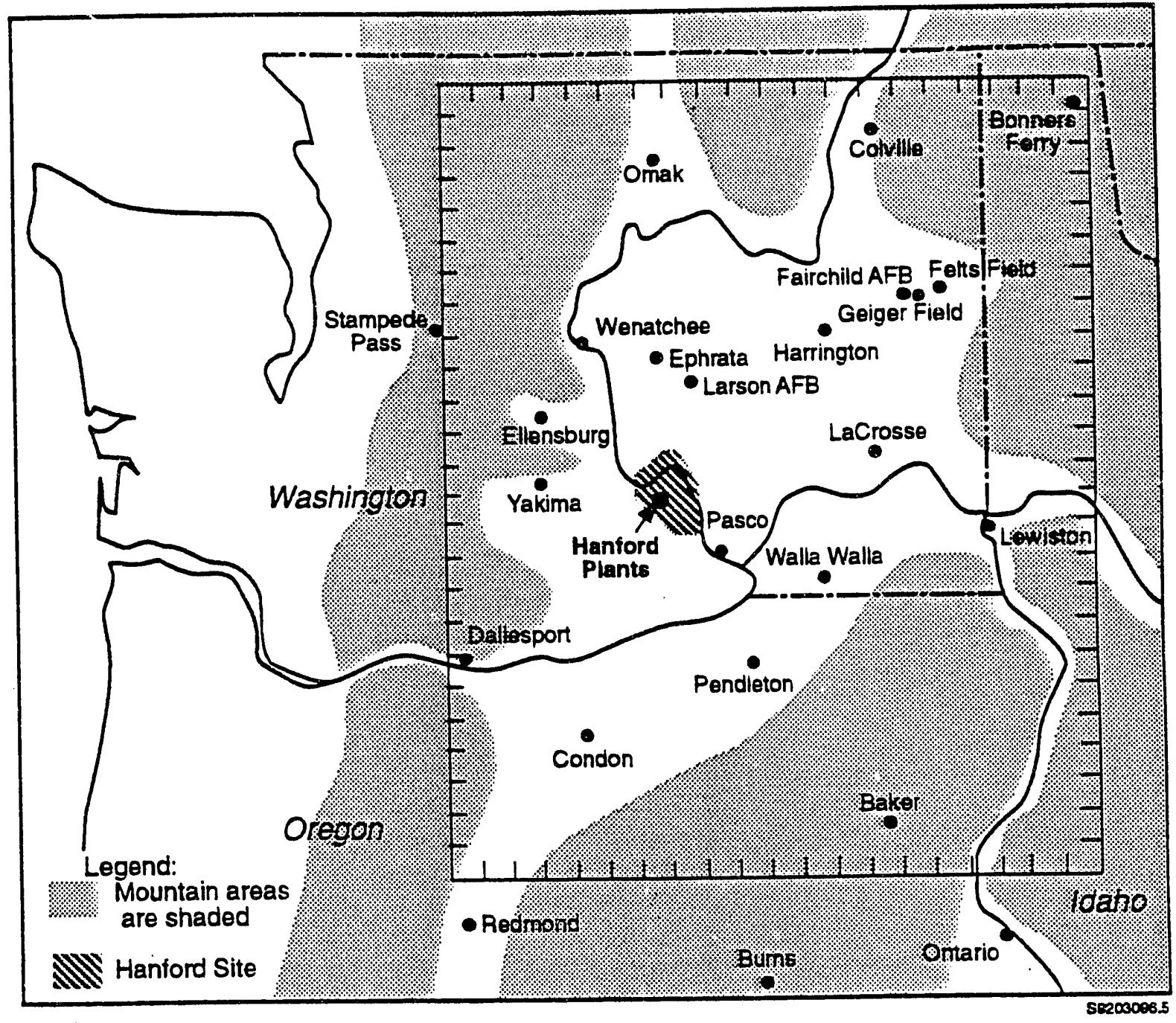

Figure 1.3. Meteorological Stations Within the HEDR Atmospheric Model Domain

average wind directions and speeds were estimated from data recorded on strip charts. In addition wind speeds were recorded in miles per hour, rather than knots.

Figure 1.3 provides an indication of the general topography in the area. More detailed topographic information is shown in the shaded relief map in Figure 1.4. These figures show the relatively flat mid-Columbia River Basin and the mountainous regions that surround it. By comparing these figures, it is apparent that many of the meteorological stations are in places where topography could have influenced the observed winds. Stage et al. (1993) discuss the potential topographic effects at each location. 


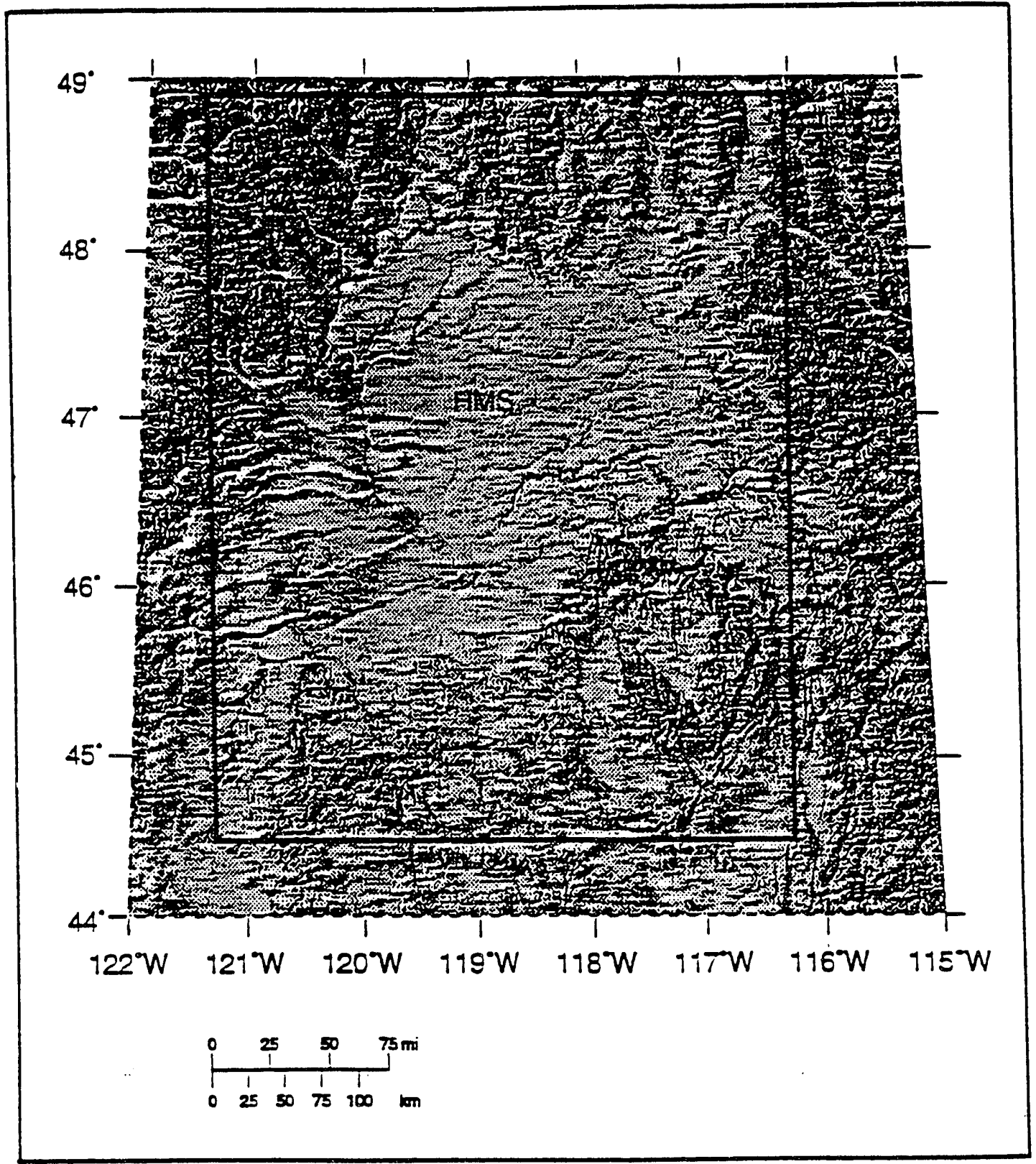

Figure 1.4. Topography of the HEDR Atmospheric Model Domain

\subsection{Wind Field Estimation}

The RATCHET computer code implements a puff diffusion model. A series of circular puffs is used to represent the plume that contains the material released to the atmosphere. Each puff is characterized by the position of its center, horizontal and vertical diffusion coefficients, and the amount of material in the puff. The wind at the center of each puff is used to calculate puff 
movement. These winds are allowed to change as a function of time and space. Therefore, the code must include a procedure for estimating the wind, from available wind data, at the positions of the puffs.

In RATCHET, wind fields are defined at equally spaced nodes within the atmospheric model domain. This type of wind field representation is called a gridded wind field. After the gridded wind field is calculated, the winds at puff positions are determined by interpolation, as needed.

Observed wind data are used to define wind fields, and the winds at puff positions are calculated from these wind fields. The wind data available for the HEDR atmospheric model domain for the 1940s were obtained using instruments of various heights between $7 \mathrm{~m}(23 \mathrm{ft})$ and $18 \mathrm{~m}(60 \mathrm{ft})$ above

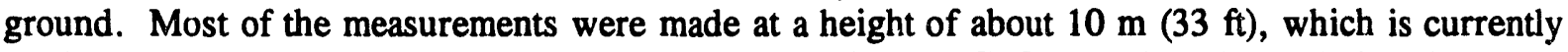
used as a standard height. Therefore, the wind fields in RATCHET are based on winds adjusted to $10 \mathrm{~m}$. Puffs are released at heights above $10 \mathrm{~m}$; as a result, the winds at the release height must be estimated from the 10-meter wind fields. A wind profile model is used to adjust winds to $10 \mathrm{~m}$ prior to estimating the wind field and to estimate winds at release height from the 10-meter wind fields. Figure 1.5 shows an idealized wind speed profile where the wind speed increases with height above the ground. The shape of real profiles is a function of atmospheric stability and surface roughness.

This report is primarily concerned with the preparation of gridded wind fields. Preparation of gridded wind fields has three steps. The first step involves adjusting measured winds to a standard reference height. In the second step, interpolation and extrapolation are combined to make an initial estimate of the field. Throughout the remainder of this report, the term interpolation implicitly includes extrapolation. The third step involves adjusting the initial gridded wind field to make the

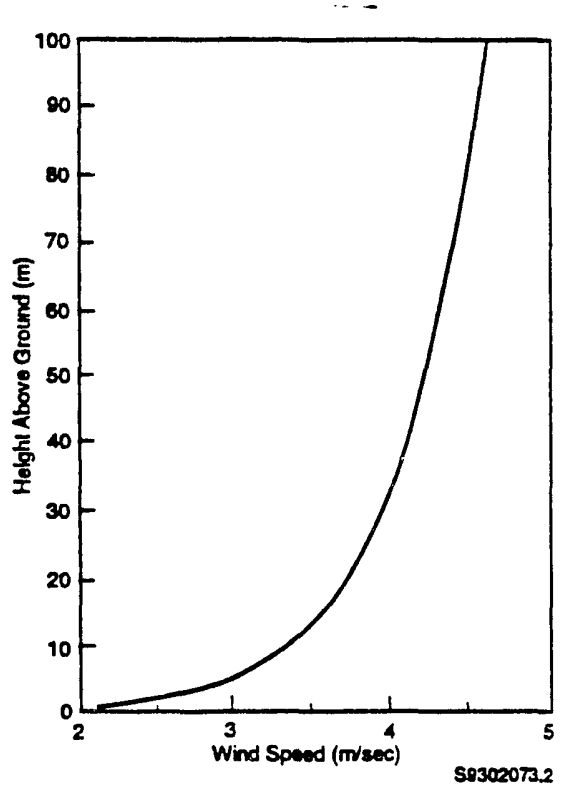

Figure 1.5. Typical Surface-Layer Wind Speed Profile 
field conform to predefined criteria such as continuity of the air mass. Many atmospheric diffusion models like RATCHET omit this third step because the adjustments are generally small, timeconsuming, and have not been shown to improve model predictions.

Usually, interpolation of wind data to the nodes of the grid is done using one of several weighted averaging techniques. In these techniques, weights are assigned to the individual wind observations as a function of distance between the grid node and the observation point. Many factors, including the number of measurement locations and the topography surrounding the stations, may be considered in selecting a weighting technique. Generally, the choice of weighting techniques is a subjective decision made by the modeler.

Figure 1.6 shows curves associated with three different weighting functions that are used to estimate the wind speed at various locations along a line between two wind measurement locations. The top panel (a) shows the weight given to the wind speed at the reference location, and the bottom one (b) shows the weight given to the wind speed at the other location. The straight lines in the figure show linear weights that cause the wind speed to change at a uniform rate from one point to the other. The curved lines show functions that give more weight to the measured wind speeds in the vicinity of the measurement location. However, increasing the weight of the measured speed in this vicinity reduces the size of the region where most of the change in speed occurs. The specific weighting functions shown are discussed in Section 3.

After an initial estimate is made of the wind field, it may be adjusted to conform to criteria established by the modeler. Frequently, adjustment techniques are used to produce wind fields commonly referred to as mass-consistent. These techniques compute a vertical motion field from the original two-dimensional horizontal wind field, constrain the vertical motions, and adjust the horizontal winds to conserve air mass. The adjustment techniques used to produce mass-consistent wind fields require information about the atmospheric structure (such as the upper-level winds, stability, and mixed-layer height) and use more sophisticated mathematics than basic interpolation methods. The RATCHET code does not adjust wind fields for mass consistency because these adjustments require significant computational time and have not been demonstrated to improve model performance.

The most advanced adjustment techniques involve the use of numerical models to predict changes in the winds. With these methods, gridded wind fields and temperatures are used to initialize a numerical model. Then, the model is used to simulate winds until the next observation period. In this way, the winds can be made to satisfy the full set of equations of motion. However, because these models require large computers and extensive calculations, their operational use is limited. They are computationally too slow for use in the HEDR Project.

\subsection{Data Quality Objectives}

Data quality objectives have been assigned to each task in the HEDR project (Shipler 1993, pp. 5.3-5.4). These objectives are stated in bold type in paragraphs 1.4.1 through 1.4.5. This report addresses matters that affect atmospheric transport modeling data quality objectives related to accuracy, precision, completeness, representativeness, and comparability. 

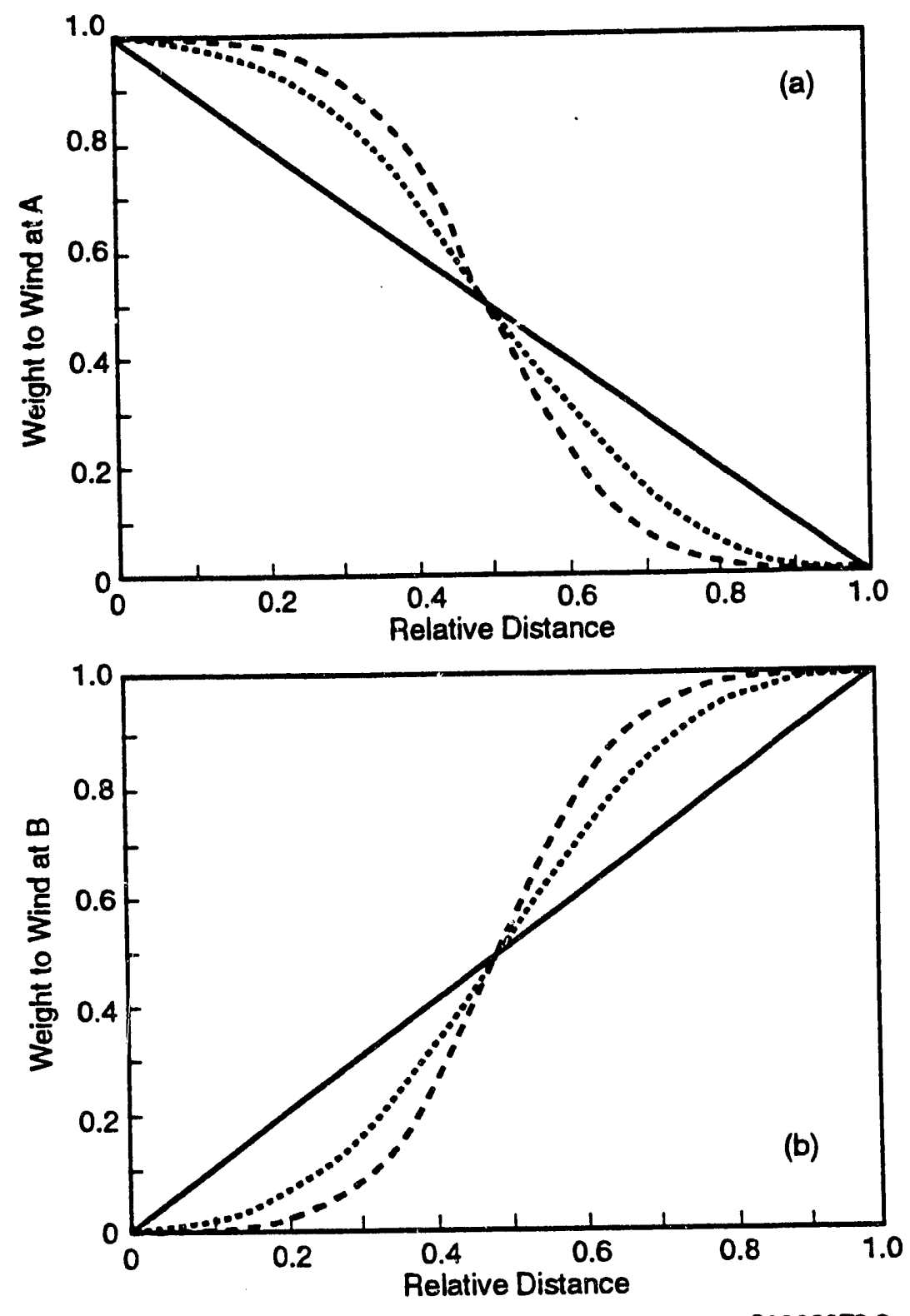

Figure 1.6. Weighting Functions Used in Wind Component Interpolation at a Reference Location(a) and Second Location(b)

\subsubsection{Accuracy}

Bias is a measure of model accuracy. It is the difference between model predictions and observed values. The objective for accuracy is that bias in monthly average air concentrations be less than a factor of three. Statistical evaluation of the stochastic 
realizations will be performed and compared to monitoring data for selected locations. A method of evaluating model bias will be determined with the assistance of project statisticians.

Estimation of wind fields can affect model accuracy by altering the position of plumes and changing the exposure duration. The Monte Carlo methods used in HEDRIC and RATCIIET will result in variations of plume positions and exposure times among model realizations. (See Meyer 1975 or Pollard 1977 for a brief discussion of Monte Carlo experiments.) The goal of the wind field modeling effort is not to avoid these variations, but to avoid systematic shifts in the position of the exposure patterns. Model evaluation studies are planned to determine the extent to which this objective has been met.

\subsubsection{Precision}

The objective is that precision will be determined stochastically from the variability built into the source term model.

Much of the variability in the time-integrated air concentrations and surface contamination results from the uncertainty in release rate estimates made in the HEDR Source Term task.

Additional variability arises from limitations of the meteorological data available for the period of interest, and uncertainty is also associated with the models used to estimate the transport, diffusion, and deposition of radionuclides in the atmosphere. The primary goal of the atmospheric modeling effort is to represent the uncertainty that exists as a result of limitations in the available data and models. Secondary goals are to avoid the introduction of additional uncertainty by use of models not supported by data and to avoid use of models that artificially reduce uncertainty.

\subsubsection{Completeness}

The objective is that the model be capable of estimating dispersion and deposition within an area approximately bounded by $49^{\circ} \mathrm{N}, 116^{\circ} \mathrm{W}, 44^{\circ} \mathrm{N}$, and $121.5^{\circ} \mathrm{W}$. Time-integrated air concentrations and surface contamination will be computed at intervals of no more than 10 miles. The code should handle deposition, plume depletion, and variable atmospheric processes. Completeness will be ensured by outside experts to identify and evaluate alternative methods and models. Peer review will be performed of the modeling techniques.

This report describes alternative methods for treating the spatial variability of the wind. Those methods are evaluated relative to the HEDR project objectives of calculating doses and their uncertainty. Available data and HEDR project computational resources are also considered in evaluating the alternatives. The report has undergone internal and external peer review.

\subsubsection{Representativeness}

The objective is for the model to account for physical phenomena that affect dispersion of material in the environment. These phenomena include transport, diffusion, wet and dry 
deposition, and radioactive decay. Outside experts will assist in identification and evaluation of methods for treating atmospheric processes in the model. The model will undergo peer review.

Spatial and temporal variations of the winds are important factors in estimating transport of material released to the atmosphere. This report describes the methods used in the initial version of the RATCHET code to represent the spatial variations in the wind and alternative methods. Changes in the treatment of spatial variations of the wind to be incorporated in the final version of RATCHET are identified in the report along with supporting rationale. The model has undergone peer review.

\subsubsection{Comparability}

The objective is that the model treat phenomena that are treated in similar, nationally accepted atmospheric dispersion models.

The initial treatment of spatial variability of winds in RATCHET was based, to a large extent, on the treatment of winds in models used by the U.S. Nuclear Regulatory Commission, the U.S. Environmental Protection Agency, and the U.S. Department of Energy. This report contains the results of a review of alternative methods for representing spatial variability of the winds.

\subsection{Report Outline}

The next section presents a description of the uncertainty in the input data used with the RATCHET code. Uncertainties are present in the available meteorological data and in the atmospheric release source terms. Section 3 describes the realistic alternatives for wind interpolation and adjustment. Section 4 discusses the alternatives, considering the available meteorological data and the source-term uncertainties. Section 5 summarizes the discussion of alternatives and lists changes to be made in the interpolation and adjustment techniques used in RATCHET. Section 6 lists the reference documents shown in the text of the report. 


\subsection{Model Uncertainty}

The HEDRIC codes, including RATCHET, are designed to account for uncertainty in input data through use of Monte Carlo techniques in which the full set of HEDRIC codes is executed a number of times using different parameter values. Parameter values for each run are selected subject to the constraint that all values must be consistent with available data. The results of each run represent one estimate of what might have actually occurred. Uncertainty is represented by the variability in results among the runs.

This section of the report describes the uncertainties in the input data available for use with the RATCHET code. Uncertainties exist in meteorological data and in the atmospheric release source term. A qualitative understanding of the uncertainties associated with the imprecision of the meteorological data and the timing of atmospheric releases provides a basis for evaluating the importance of other uncertainty sources. The last part of the section presents preliminary results from 100 realizations of the RATCHET code for 1945 . These results provide an indication of the ranges of time-integrated air concentrations that result from incorporating uncertainty in the model.

\subsection{Wind Data Uncertainty}

The initial RATCHET code explicitly treats one form of wind data uncertainty, imprecision in the recorded values. The wind data for each station consist of a wind direction sector, typically $22.5^{\circ}$ wide, and a wind speed that is recorded as an integer. As the hourly data for each station are read by the code, a specific wind direction within the reported wind direction sector is randomly selected as an estimate of the actual average direction for the hour. Similarly, a wind speed is selected that is within the range of precision of the recorded value. The width of wind sectors is $22.5^{\circ}$. The precision of the wind speeds is $\pm 0.5 \mathrm{kn}$, except for the HMS which reports wind speeds in miles per hour. The precision of the HMS wind speeds is $\pm 0.5 \mathrm{mph}$. The random wind direction and speed components differ from station to station, hour to hour, and run to run.

Two additional sources of uncertainty in wind data are not accounted for in RATCHET. The first of these is uncertainty associated with winds at low wind speeds, and the other is the uncertainty associated with using a 1-minute observation to represent an hourly average.

For wind speeds near the threshold of the instruments, large uncertainties are present in both the direction and speed. Schere and Coates (1992) assume that uncertainty in both wind speed and direction are related to the reported wind speed. In their model, the uncertainty in speed varies from $2 \mathrm{~m} / \mathrm{sec}(4.5 \mathrm{mph})$ in calm conditions to $1 \mathrm{~m} / \mathrm{sec}(2.2 \mathrm{mph})$ at high speeds. For near calm conditions, the wind direction is randomly varied through $360^{\circ}$. As the wind speed increases, the random variability in wind directions decreases to a few degrees (less than $6^{\circ}$ when the wind speed is $10 \mathrm{~m} / \mathrm{sec}$ [22 mph]).

The procedure described by Schere and Coates (1992) is not directly transferrable to RATCHET because of the coarseness of the wind direction data available for use in the HEDR Project. The uncertainty associated with wind directions in the HEDR database, due to imprecision of the recorded 
values, exceeds the uncertainty estimated by Schere and Coates' procedure during high wind speeds. However, when RATCHET is revised, a modified version of their procedure will be incorporated to improve the representation of wind speed and direction uncertainty during low wind speed conditions.

The RATCHET code does not account for the uncertainty associated with using 1-minute observations to represent hourly average winds. Hourly data from Hanford, Walla Walla, and Spokane (Fairchild AFB) have been examined in an effort to estimate the magnitude of uncertainty associated with 1-minute observations. These uncertainty estimates have been compared with the uncertainties in other parameters to evaluate the significance of omitting treatment of the uncertainty in the 1 -minute observations.

The uncertainty in the 1-minute observations is expected to be somewhat less than the change in wind direction from one hour to the next. Figure 2.1 shows the frequency distributions for the differences in wind directions for HMS observations separated by $1,2,6$, and 12 hrs. The distribution for a 1-hour time lag (observations separated by one hour) provides a qualitative indication of the magnitude of the uncertainties that might be associated with the use of 1-minute observations. The standard deviation of wind direction differences represented in this distribution is about $40^{\circ}$. However, the wind direction data for HMS are estimates of hourly averages taken from

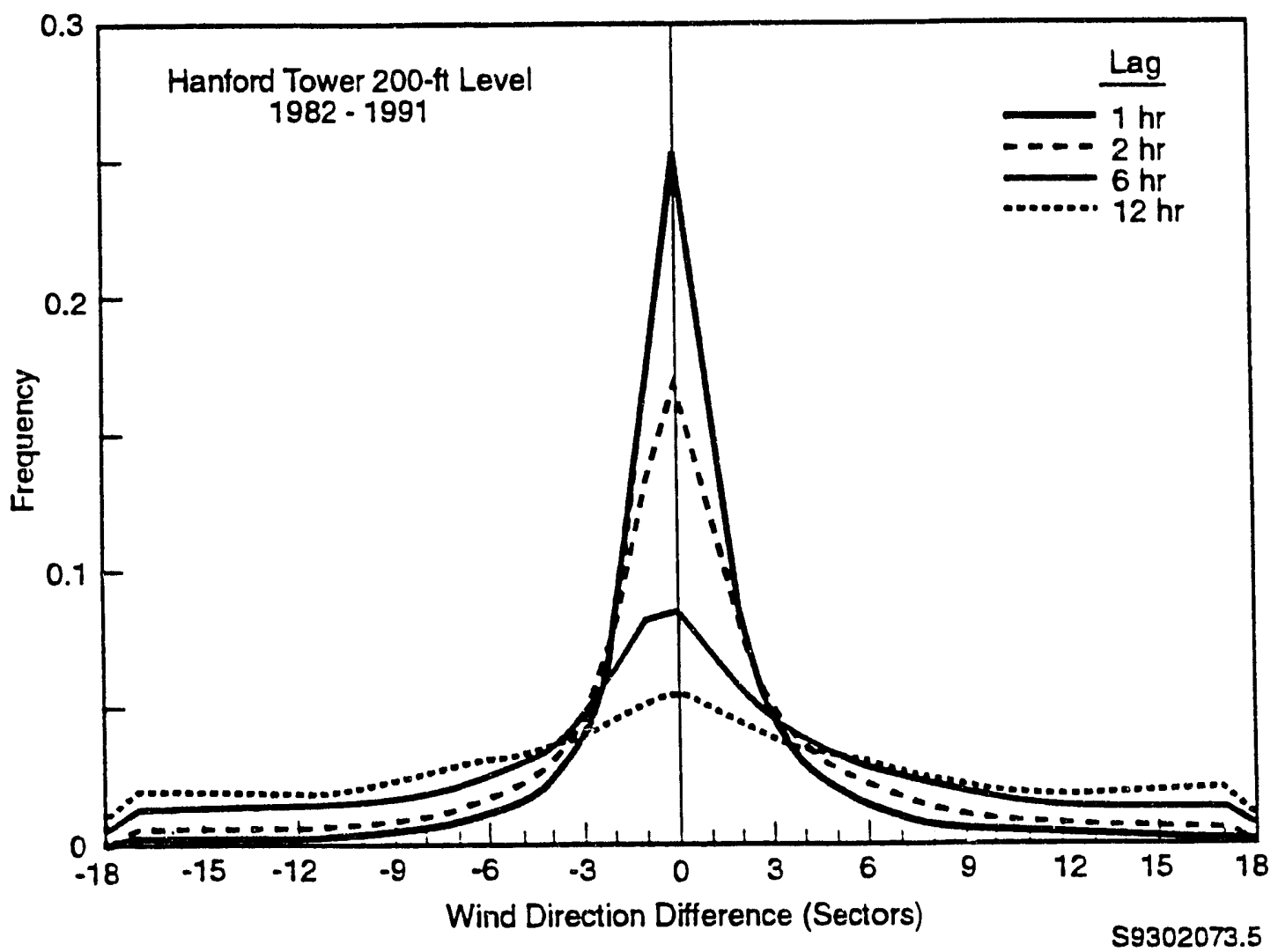

Figure 2.1. Frequency of Wind Direction Shifts at the HMS Tower 
continuous wind direction records, not 1-minute observations. Larger uncertainty might be expected in observations from the remaining stations.

Wind data for 1945 through 1947 from Walla Walla and Fairchild AFB are based on 1-minute observations. Standard deviations of the differences in wind directions between consecutive observations at these locations are $47^{\circ}$ and $38^{\circ}$, respectively. Thus, the uncertainty in directions represented by the standard deviation of direction differences at these stations is about the same magnitude as the uncertainty estimated from the HMS data.

\subsection{Hourly Release Rate Uncertainty}

Heeb (1993) describes the estimation of the hourly iodine-131 release rates that are used as input to RATCHET. Each series of estimated release rates is uncertain due to uncertainties in the times that specific releases started and the amount of iodine-131 released. The uncertainty in the release start times, which is typically about the length of one work shift (8 hrs), varies from a few hours to a day or two. Assuming the differences in release start times can be associated with the time lags between wind observations, the uncertainty in start times has an approximate equivalent in uncertainty in wind direction.

Wind direction data from the 200-foot level of the HMS tower, Walla Walla, and the Fairchild AFB have been examined to assess the relationship between uncertainty in release time and uncertainty in wind direction. Figure 2.1 shows the frequency distributions for the differences in wind directions at the 200-foot level of the HMS tower for observations separated by $1,2,6$, and $12 \mathrm{hrs}$. In each case, the distribution is approximately symmetrical with the mode (maximum frequency at zero). However, the width of the distribution increases as the time between observations (lag) increases. The standard deviations of the differences for lags from 0 through $24 \mathrm{hrs}$ are shown in Figure 2.2. The standard deviation reaches a maximum for lags of about $12 \mathrm{hrs}$. This maximum, along with the decrease in standard deviation for longer lays, is caused by diurnal wind patterns. Wind directions for 1945 through 1947 from Walla Walla and Fairchild AFB were also examined.

The frequencies that wind directions from observations made $8 \mathrm{hrs}$ apart fall within a common sector have been determined from wind data from HMS, Walla Walla, and Fairchild AFB. Figure 2.3 shows how this frequency increases as the sector width increases. The sector width must be increased to about $90^{\circ}$ before there is a 50 percent likelihood the directions will be in the same sector. Again assuming that uncertainty in release start times can be associated with time lags between observations, Figure 2.3 indicates the wind direction uncertainty associated with an 8-hour uncertainty in release times is $80^{\circ}$ to $100^{\circ}$.

A rough comparison can now be made between the uncertainty in the use of 1-minute observations to represent hourly average winds and the uncertainty associated with release times. Figure 2.4 shows the change frequencies of consecutive hourly wind direction observations falling in a common sector with change in sector width. Approximately 50 percent of the time, the wind directions in consecutive observations will be within a sector $30^{\circ}$ wide. If this width represents the 


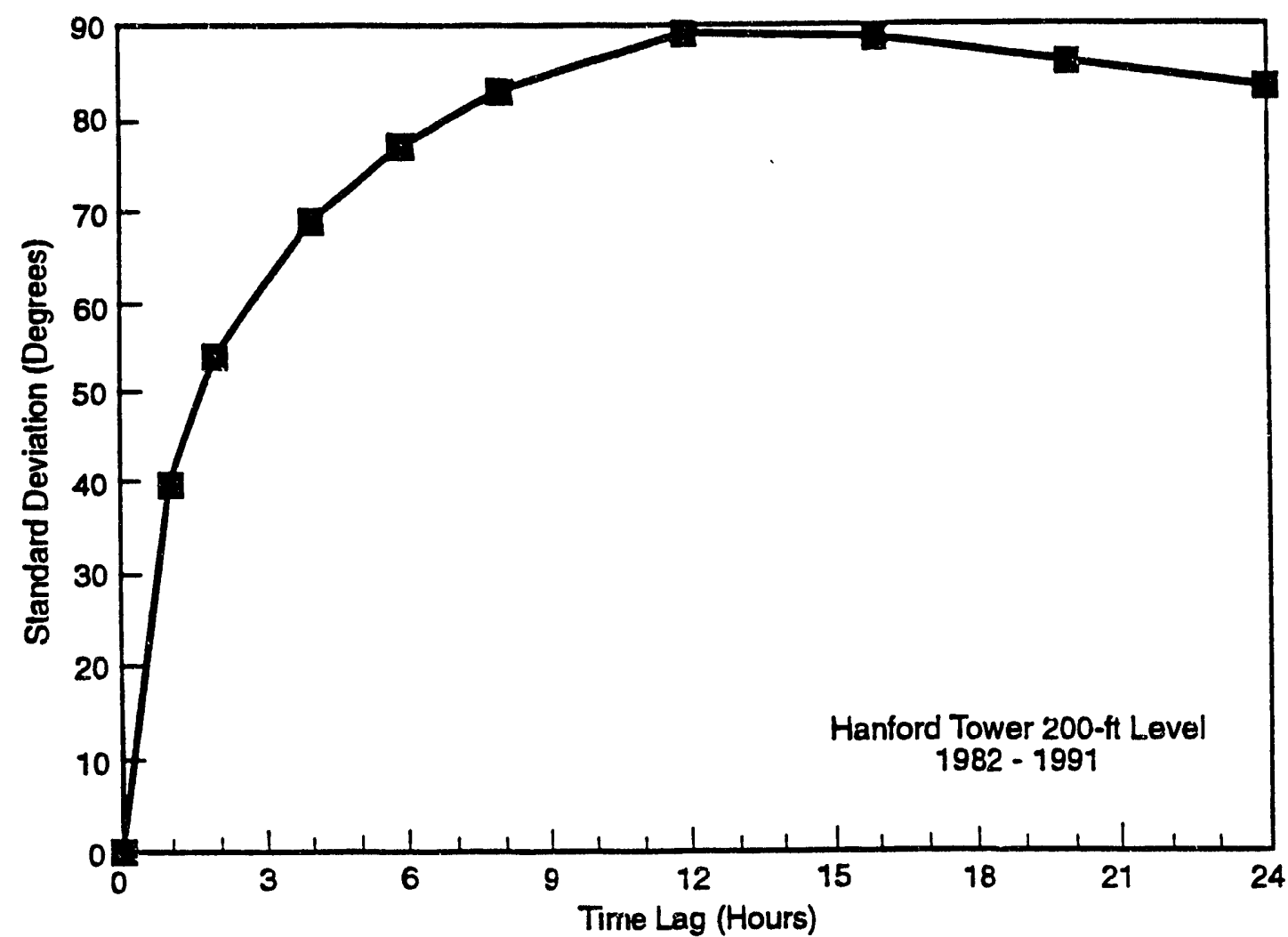

$\$ 9302073.8$

Figure 2.2. Standard Deviation of Wind Direction Differences as a Function of Time Lag

uncertainty assosiated with 1-minute observations and the $90^{\circ}$ sector width from Figure 2.3 represents the uncertainty associated with release times, the uncertainty in release times is much more significant than the uncertainty in the 1-minute observations. Assuming that standard deviations are proportional to the sector widths, the contribution of uncertainty in release times to the overall uncertainty in puff transport should be about 9 times the contribution of the uncertainty due to 1-minute observations.

\subsection{Preliminary Estimates of Model Output Variability}

The uncertainties in wind direction resulting from uncertainties in release times are large. These uncertainties, which are directly related to the initial transport direction, might be unacceptably large if the HEDR Project were estimating hourly dose estimates. However, the project is primarily concerned with annual doses. Therefore, it is appropriate to ask how estimates of annual timeintegrated air concentrations and surface contamination vary in response to model input uncertainty.

The RATCHET code has generated 100 realizations of time-integrated air concentrations and surface contamination for use in model evaluation studies. Figure 2.5 shows the locations of 43 nodes that have been given names within the atmospheric model domain. Figure 2.6 provides an 


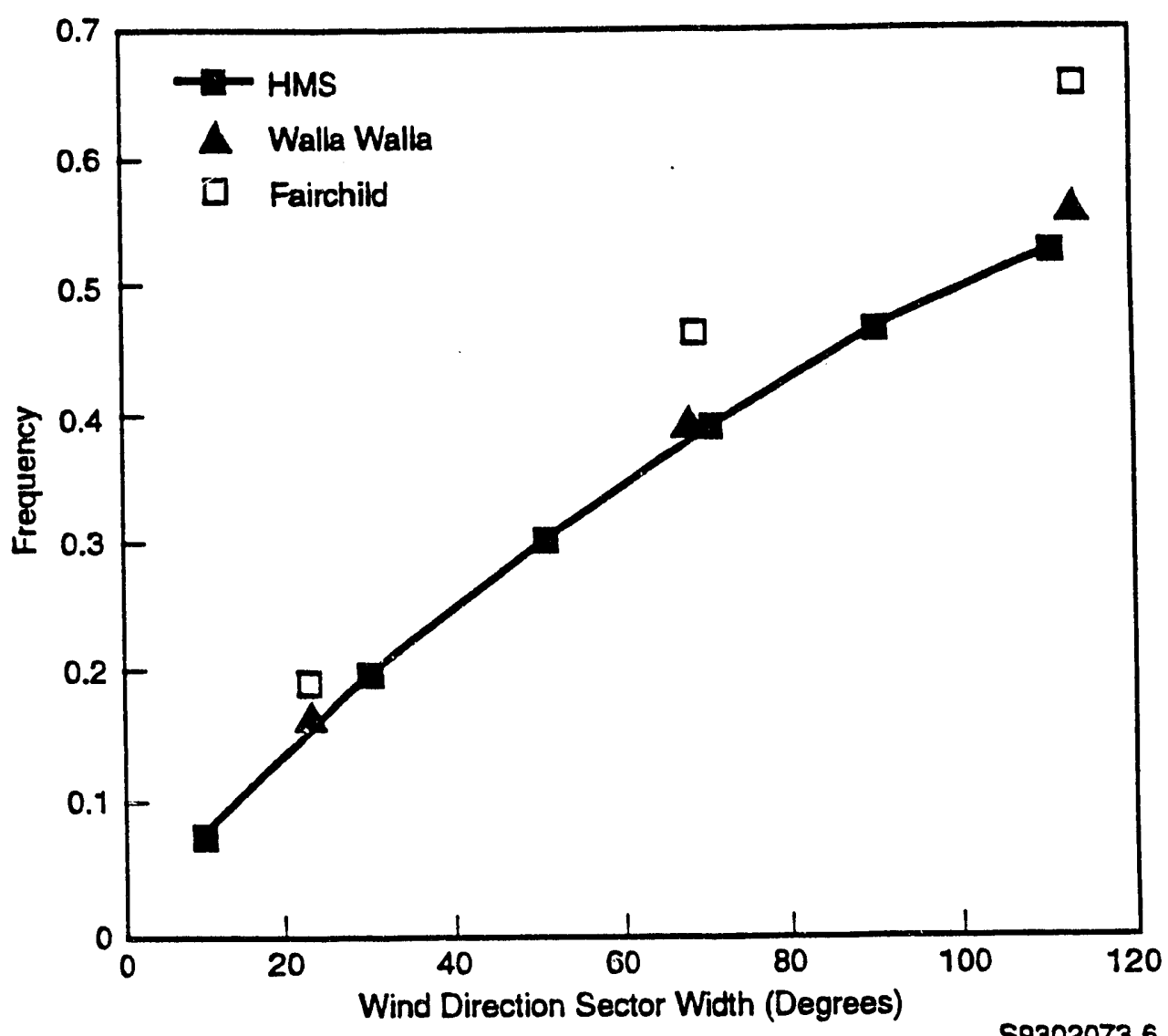

Figure 2.3. Cumulative Frequency of Wind Direction Differences for Observations Separated by Eight Hours (HMS, Walla Walla, and Fairchild AFB)

indication of the geographical pattern of time-integrated air concentrations ( $\left.\mathrm{Ci}-\mathrm{sec} / \mathrm{m}^{3}\right)$ based on median values of the 100 realizations at the 43 named nodes. In Figures 2.5 and 2.6, the notation $B$ and $T$ Plant refers to the two separation plants located at the Hanford site that were the sources of iodine releases in the 1940 s.

The pattern in Figure 2.6 is consistent with patterns found in previous studies of transport from Hanford (Hilst 1951a; Nickola 1951, 1952, 1953). This consistency gives some assurance that major errors are absent from the processing of wind data in RATCHET. However, Figure 2.6 does not indicate the range of time-integrated air concentrations at each node within the 100 realizations. Table 2.1 lists the 10th, 50th, and 90th percentile time-integrated air concentrations for each node as determined from the 100 realizations. At 28 of the 43 named nodes, the 90 th percentile timeintegrated air concentration was less than two times larger than the 10th percentile value. At only one node (Meadows, Idaho) did the 90 th percentile value exceed the 10th percentile value by more than a factor of 5. This node, in the extreme southeast corner of the model domain, also has the lowest median time-integrated concentration of the $\mathbf{4 3}$ named nodes. 


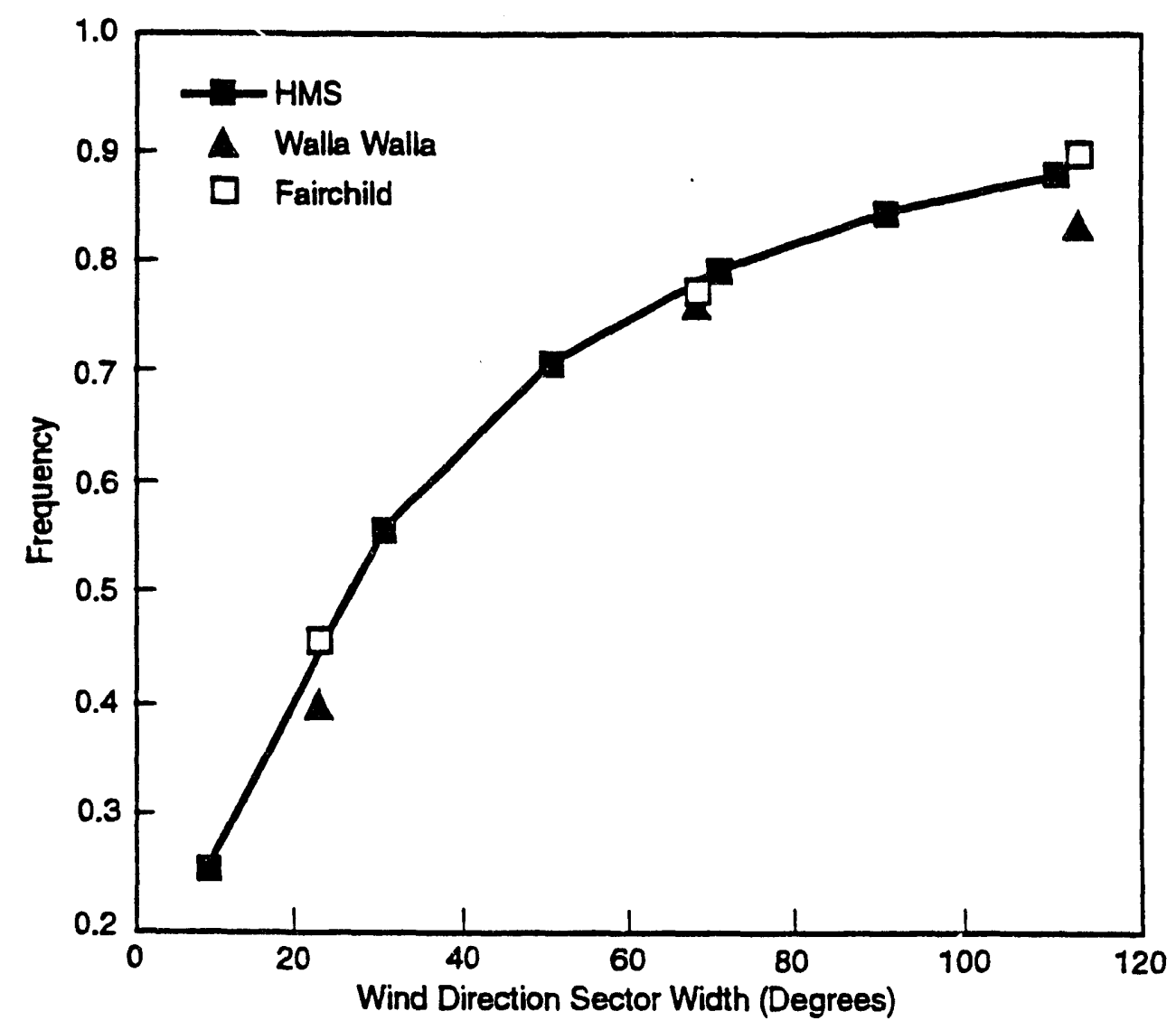

59302073.7

Figure 2.4. Frequency of Consecutive Wind Direction Observations in a Common Sector (HMS, Walla Walla, and Fairchild AFB

The values in Table 2.1 clearly show that rather large uncertainties in the hourly release rates and station winds do not result in large variations of annual time-integrated air concentrations between model realizations. Over time, the integration performed by the model filters out most of the variability in model input. This is consistent with the improvement in dispersion model performance found in model evaluation studies (Weber et al. 1982; Carhart et al. 1989; Klug et al. 1992). The improved performance of dispersion models can be interpreted as an indication that climatological wind patterns are more important for estimating dispersion of continuing long-term releases than individual hourly wind patterns. 


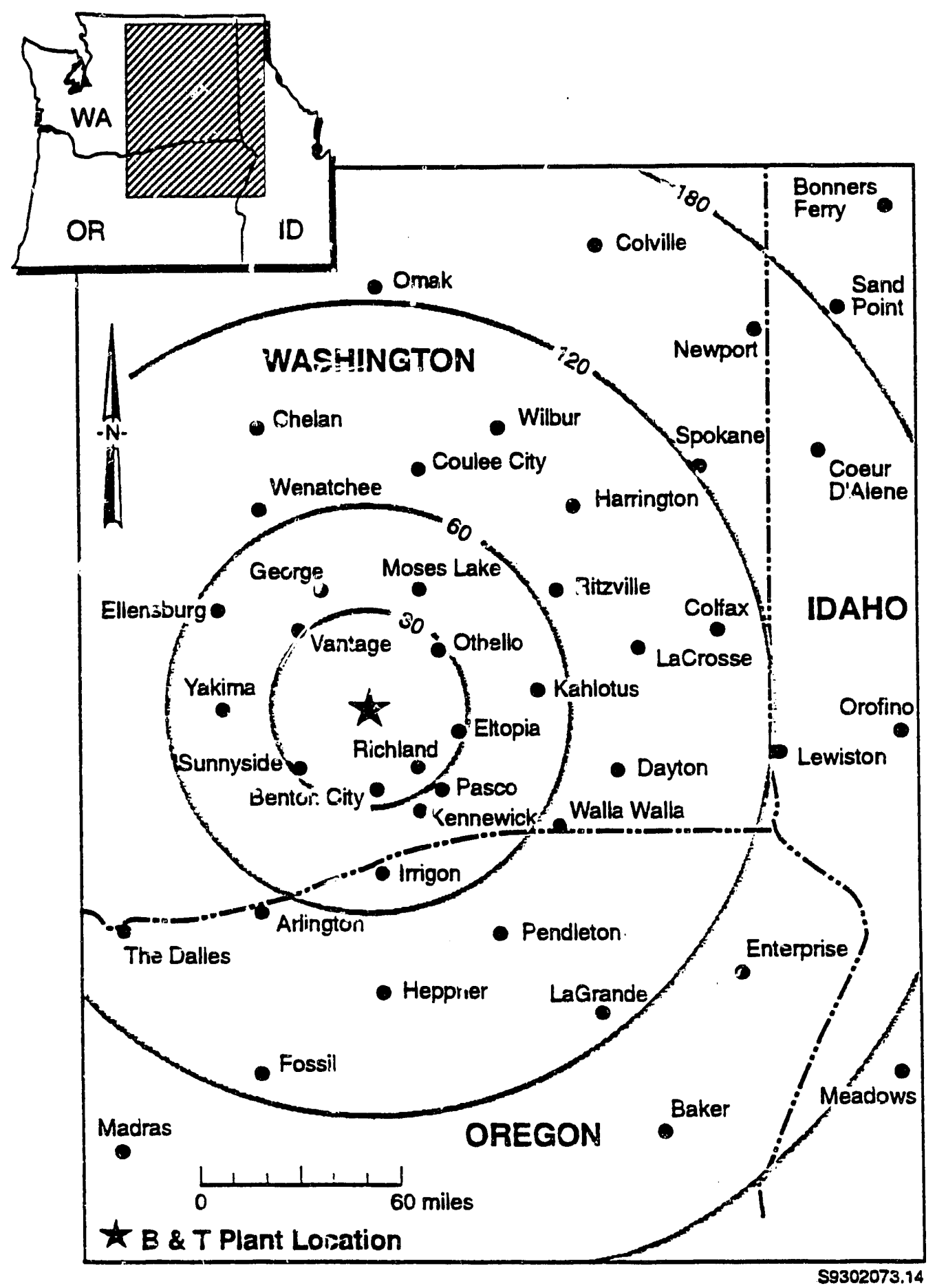

Figure 2.5. Named Node Locations - HEDR Atmospheric Model Domain 


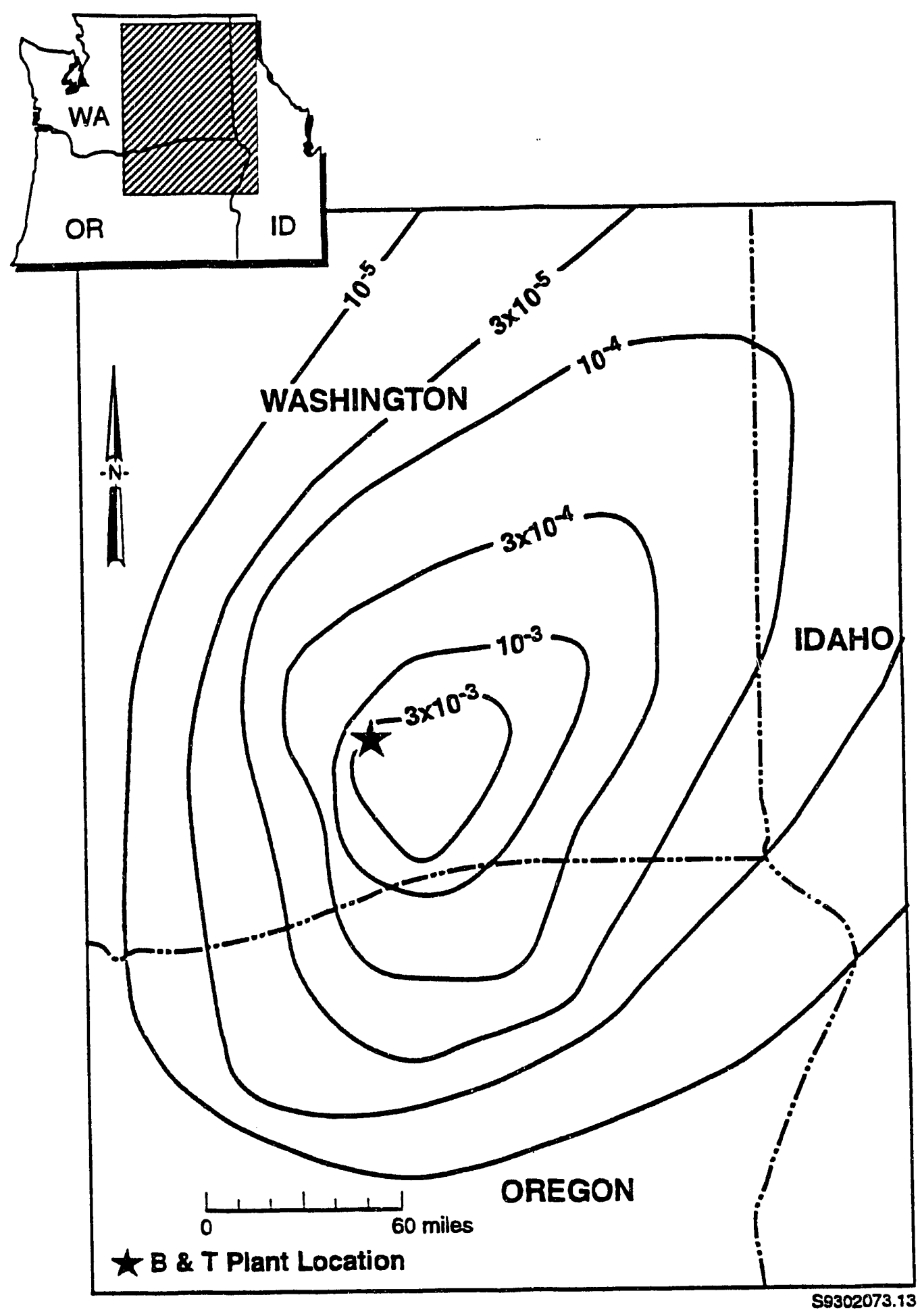

Figure 2.6. Geographical Pattern of Median Iodine-131 Time-Integrated Air Concentrations $\left[(\mathrm{Ci}-\mathrm{sec}) / \mathrm{m}^{3}\right](1945)$ 
Table 2.1. Time-Integrated Air Concentrations $\left[(\mathrm{Ci}-\mathrm{sec}) / \mathrm{m}^{3}\right], 1945$

Percentile

\begin{tabular}{|c|c|c|c|c|}
\hline \multirow{2}{*}{ Node Name } & & & & \\
\hline & 10th & 50th & 90th & 90th/10th \\
\hline Benton City, WA & $1.85 \mathrm{e}-3$ & $2.61 \mathrm{e}-3$ & $4.37 e-3$ & 2.36 \\
\hline Chelan & $1.03 e-5$ & $1.60 \mathrm{e}-5$ & $2.67 e-5$ & 2.59 \\
\hline Colfax & $1.64 e-4$ & $2.18 e^{-4}$ & $2.68 \mathrm{e}-4$ & 1.63 \\
\hline Colville & $6.60 e-5$ & $8.20 e-5$ & $1.12 e-4$ & 1.70 \\
\hline Coulee City & $8.68 e-5$ & $1.17 e^{-4}$ & $1.64 e-4$ & 1.89 \\
\hline Dayton & $1.85 e-4$ & $2.34 e-4$ & $3.10 e-4$ & 1.68 \\
\hline Ellensburg & $4.09 e-5$ & $5.80 \mathrm{e}-5$ & $9.42 \mathrm{e}-5$ & 2.30 \\
\hline Eltopia & $5.66 \mathrm{e}-3$ & $7.08 e-3$ & $8.64 e-3$ & 1.53 \\
\hline George & $9.69 e-5$ & $1.42 e-4$ & $1.93 e-4$ & 1.99 \\
\hline Harrington & $2.46 \mathrm{e}-4$ & $3.00 e-4$ & $4.00 e-4$ & 1.63 \\
\hline Kahlotus & $1.58 \mathrm{e}-3$ & $1.89 e-3$ & $2.42 \mathrm{e}-3$ & 1.53 \\
\hline Kennewick & $2.96 e-3$ & $3.58 \mathrm{e}-3$ & $4.53 e-3$ & 1.53 \\
\hline LaCrosse & $4.06 e-4$ & $5.14 e-4$ & $6.49 e-4$ & 1.60 \\
\hline Moses Lake & $2.74 e-4$ & $3.58 \mathrm{e}-4$ & $5.33 e-4$ & 1.95 \\
\hline Newport & $9.50 e-5$ & $1.15 e^{-4}$ & $1.42 e-4$ & 1.50 \\
\hline Omak & $9.94 e-6$ & $1.69 e-5$ & $2.90 \mathrm{e}-5$ & 2.92 \\
\hline Othello & $9.72 e-4$ & $1.24 e-3$ & $1.54 e-3$ & 1.58 \\
\hline Pasco & $3.70 \mathrm{e}-3$ & $4.40 e-3$ & $5.38 \mathrm{e}-3$ & 1.45 \\
\hline Richland & $6.42 e-3$ & $7.92 e-3$ & $9.66 e-3$ & 1.50 \\
\hline Ritzville & $6.12 e-4$ & $7.40 e-4$ & $9.48 e-4$ & 1.55 \\
\hline Spokane & $1.70 e-4$ & $2.04 e-4$ & $2.53 e-4$ & 1.49 \\
\hline Sunnyside & $1.85 e-4$ & $2.52 e-4$ & $3.47 e-4$ & 1.88 \\
\hline Vantage & $2.27 e-4$ & $3.07 e-4$ & $4.07 e-4$ & 1.79 \\
\hline Walla Walla & $2.88 e-4$ & $4.02 e-4$ & $5.56 e-4$ & 1.93 \\
\hline Wenatchee & $1.06 e-5$ & $1.76 e-5$ & $2.77 e-5$ & 2.61 \\
\hline Wilbur & $8.44 e-5$ & $1.17 e-4$ & $1.62 e-4$ & 1.92 \\
\hline Yakima & $2.36 e-5$ & $4.05 e-5$ & $6.46 e-5$ & 2.74 \\
\hline Arlington, $\mathrm{OR}$ & $3.16 \mathrm{e}-5$ & $4.71 e-5$ & $6.30 \mathrm{e}-5$ & 1.99 \\
\hline Baker & $4.08 e-6$ & $7.90 e-6$ & $1.24 \mathrm{e}-5$ & 3.04 \\
\hline The Dalles & $5.46 \mathrm{e} .6$ & $1.03 e-5$ & $1.73 e-5$ & 3.17 \\
\hline Enterprise & $6.22 e-6$ & $1.02 e-5$ & $1.60 \mathrm{e}-5$ & 2.57 \\
\hline Fossil & $3.59 e-5$ & $5.16 e-5$ & $7.80 e-5$ & 2.17 \\
\hline Heppner & $1.79 e-4$ & $2.34 e-4$ & $3.14 e-4$ & 1.75 \\
\hline Irrigon & $7.28 e-4$ & $9.09 e-4$ & $1.20 \mathrm{e}-3$ & 1.65 \\
\hline LaGrande & $1.68 \mathrm{e}-5$ & $2.33 e-5$ & $3.44 e-5$ & 2.05 \\
\hline Madras & $4.48 e-6$ & $6.86 e-6$ & $1.02 e-5$ & 2.28 \\
\hline Pendleton & $3.96 e-4$ & $5.40 e-4$ & $6.38 e-4$ & 1.61 \\
\hline Bonners Ferry, ID & $3.37 e-5$ & $4.28 e-5$ & $5.60 \mathrm{e}-5$ & 1.66 \\
\hline Coeur d'Alene & $5.38 \mathrm{e}-5$ & $6.71 e-5$ & $8.46 \mathrm{e}-5$ & 1.57 \\
\hline Lewiston & $5.96 e-5$ & $8.91 \mathrm{e}-5$ & $1.32 e-4$ & 2.22 \\
\hline Meadows & $7.48 \mathrm{e}-7$ & $1.57 e-6$ & $3.86 e-6$ & 5.16 \\
\hline Orofino & $1.48 \mathrm{e}-5$ & $2.15 e-5$ & $3.08 \mathrm{e}-5$ & 2.08 \\
\hline Sandpoint & $4.77 e-5$ & $5.97 e-5$ & $7.62 e-5$ & 1.60 \\
\hline
\end{tabular}




\subsection{Wind Field Models}

Observed wind data are rarely available for precisely the location for which they are needed. Therefore, meteorological models like RATCHET must include a method for interpolating or extrapolating the available data. Some models use polynomial functions, fitted to the available data, to represent wind fields. However, most models interpolate the available data to nodes in a fixed grid to represent the wind field, and then use the gridded wind field for transport calculations. RATCHET is in the latter class of models.

This section of the report describes the common methods used to prepare gridded wind fields. The methods described include both horizontal and vertical interpolation and extrapolation of wind data. Adjustment of gridded wind fields to achieve mass continuity is also described. These methods cover the range of alternatives considered for incorporation in the revision of RATCHET. Section 4 covers the evaluation and selection of methods for RATCHET.

Data interpolation and extrapolation techniques involving transform functions (Lamb and Hati 1987), polynomial basis functions (Allwine and Whiteman 1985), and data assimilation (Yamada and Bunker 1988; Andres 1990) are not addressed because their computational requirements exceed HEDR Project resources. Pielke (1989) provides additional rationale for not considering data assimilation by stating that it may be impossible to determine an accurate initial state for the model.

\subsection{Interpolation Methods}

The interpolation process involves adjusting the observed winds to standard heights, converting the winds from direction and speed to east-west and north-south components, and interpolating to grid nodes. When wind data are available for several levels, the process is repeated at each level. If wind data are not available at the heights of interest, vertical extrapolation may be needed. This section discusses both vertical and horizontal interpolation methods.

\subsubsection{Vertical Interpolation of Winds}

Near the earth's surface, in the area referred to as the planetary boundary layer, the wind changes as a function of height above ground as a result of friction at the surface. In the layer of air closest to the ground, the change is primarily in the wind speed. The depth of this surface layer varies as a function of atmospheric stability. Panofsky and Dutton (1984 pp. 113-114) suggest that surface layer assumptions are valid to a height of at least $100 \mathrm{~m}(330 \mathrm{ft})$ during the day, but may not

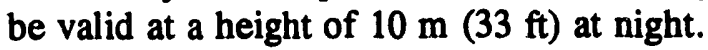

Generally, wind data are not obtained from measurements at standard heights above ground. Therefore, the first step in producing an initial estimate of the gridded wind field is to adjust the available wind data to standard heights. Surface-level wind measurements during the primary period of interest to the HEDR Project were made at heights between 7 and $18 \mathrm{~m}$ ( 23 and $60 \mathrm{ft}$ ) above the ground. Adjustments of wind data to a standard height within this range may be made using a wind 
profile equation. Panofsky and Dutton (1984, pp. 131-139) describe the common profile equations. However, note the adjustment is limited to wind speed; wind directions are not adjusted.

Both wind speed and direction change with height above the surface layer. Consequently, the variation of wind direction with height should be considered in wind adjustment at higher levels in the planetary boundary layer. If upper-level wind data exist, such data can be used to estimate wind direction and speed changes. Otherwise, estimation of direction and speed changes with height in the absence of upper-level winds requires information on, or assumptions related to, mixing-layer height, atmospheric stability, pressure and temperature gradients, and local topography.

With a rather restrictive set of assumptions, the equations of motion for the atmosphere can be simplified to give a wind profile known as the Ekman spiral. The Ekman spiral accounts for changes in wind direction, as well as wind speed between the surface wind and the wind at the top of the mixing layer. The wind at the top of the mixing layer is assumed to be equal to the geostrophic wind. The geostrophic wind results from a balance between the pressure gradient and Coriolis forces in the atmosphere. However, according to Stull (1988, p. 214), the conditions leading to the Ekman spiral rarely exist. Stull further states the Ekman spiral is only qualitatively correct in neutral conditions, is not observed in unstable conditions, and is not even qualitatively correct in stable conditions.

ApSimon et al. (1985) use a simple algorithm to estimate the geostrophic wind from surface observations. In effect, ApSimon et al. assume the geostrophic wind speed is proportional to the

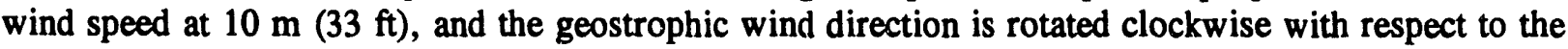
surface direction. The amount of rotation is given as a function of surface type and atmospheric stability. Wind directions and speeds at heights between $10 \mathrm{~m}$ and the top of the boundary layer are calculated using interpolation formulas.

ApSimon et al. (1985) note that a considerable variation is present in the turning of the wind with height, particularly in stable conditions, and that their wind direction adjustment would lead to trajectories that would be inadequate if concentration predictions were required on specific occasions. Among the factors cited as potential causes of inaccuracies were frontal zones and departures from the assumptions associated with the geostrophic wind model.

Another method of estimating the changes of wind direction with height in the absence of upperlevel wind data is to use pressure data to calculate the geostrophic wind. Sykes and Hatton (1976) discuss calculating pressure fields and the geostrophic wind from sea-level pressure data for a model domain about 25 times larger than the HEDR model domain. According to Sykes and Hatton (1976), the assumption that winds based on the surface geostrophic wind will describe the trajectory material in the boundary layer is a potential source of errors. In addition, they estimated the probable errors in geostrophic winds caused by uncertainties in the pressure field. These errors are a function of the scale of the features being resolved. For a feature with a length scale of $100 \mathrm{~km}(62 \mathrm{mi})$, the error in component speeds was about $1 \mathrm{~m} / \mathrm{sec}(2.2 \mathrm{mph})$. For smaller scale features, the errors would be larger.

Sykes and Hatton do not consider the errors associated with reduction of observed station pressure to sea level. They also ignore the effects of warm or cold air advection on the geostrophic wind. Warm or cold air advection causes the geostrophic wind to vary with height above ground. 
Thus, the errors associated with estimating the geostropic wind from pressure measurements in the HEDR atmospheric model domain are larger than the errors described by Sykes and Hatton.

\subsubsection{Horizontal Interpolation of Winds}

Wind directions are expressed in degrees and range from $000^{\circ}$ north to $359^{\circ}$ ( $1^{\circ}$ west of north). As a result, averaging wind directions is incorrect. For example, if the one direction is just west of north, for instance $355^{\circ}$, and the other is just east of north, $005^{\circ}$, the result is near south $\left(180^{\circ}\right)$. Consequently, Cartesian (east-west and north-south) components of the wind vector, rather than wind direction and speed, are used for horizontal interpolation of the winds. The transformation from direction and speed to Cartesian components uses

$$
\mathrm{u}=-\mathrm{s} \sin \theta
$$

and

$$
v=-s \cos \theta
$$

where $u$ is the east-west component of the vector (positive for transport to the east), $v$ is the northsouth component (positive for transport to the north), $\mathrm{s}$ is the wind speed, and $\theta$ is the wind direction.

Given the $u$ and $v$ wind components at reporting stations, the common method of obtaining an initial wind field estimate is interpolation using a weighted average,

$$
C_{i j}=\sum_{k=1}^{n} C_{k} W_{k}(r) / \sum_{k-1}^{n} W_{k}(r)
$$

$$
\text { where } \begin{aligned}
\mathrm{C}_{\mathrm{ij}} & =\text { the wind component (either } \mathrm{u} \text { or } \mathrm{v} \text { ) } \\
\mathrm{ij} & =\text { grid node } \\
\mathrm{C}_{\mathrm{k}} & =\text { observed wind component at the station } \mathrm{k} \\
\mathrm{n} & =\text { total number of stations } \\
\mathrm{W}_{\mathrm{k}}(\mathrm{r}) & =\text { weighting function } \\
\mathrm{r} & =\text { distance from the grid point to the station. }
\end{aligned}
$$

This scheme is easy to implement and is widely used in applications where fast wind-field estimation is a priority.

Several methods have been proposed for determining the weights used in horizontal interpolation. Goodin et al. (1979) discuss both interpolation and weighting methods. Among the methods discussed are $1 / \mathrm{r}^{\mathrm{n}}$ weighting, and more complicated functions, such as exponentials and fitted polynomials. In general, weights are inversely related to the distance between the node and the observation point. 
The set of weighting factors in most common usage is simply

$$
W_{k}(r)=\frac{1}{r^{n}}
$$

where $\mathrm{n}$ is 1,2 , or 3 . This weighting scheme may be modified by establishing an arbitrarily assigned radius of influence $(R)$ and setting the weight to zero when the distance exceeds $R$ (Wendell 1972; Goodin et al. 1980).

The usual value of $\mathbf{n}$ is 2 . However, the choice of $\mathbf{n}$ should depend on the characteristics of the observing station. For example, when data are very sparse, such as upper-level data over a mesoscale region, a $1 / \mathrm{r}$ weighting can be used to obtain smooth variations in the wind field. On the other hand, use of $1 / r^{2}$ or $1 / r^{3}$ weighting increases the weight given to a wind observation near its measurement point and decreases the iveight as other wind measurement points are approached. With a dense station network, using an exponential of $1 / \mathrm{r}^{3}$ weighting may be appropriate to limit the radius of influence of each station and preserve sharp features, such as fronts.

Figure 3.1 shows the variation of weights given to winds between two measurement points for $1 / r, 1 / r^{2}$, and $1 / r^{3}$ weighting. This figure shows that increasing $n$ increases the weight given to measured winds near their measurement point. It also shows that increasing $\mathbf{n}$ decreases the region in which transitions take place. Note that all of these schemes give equal weights to winds from two stations at a point equidistant from the stations. Figure 3.2 shows an example of the effect of two different weighting factors on transport fields derived from the same observed winds. The fields in the example are based on winds observed at 1500 PST, December 19, 1944. The field shown in Figure 3.2(a) was derived using $1 / \mathrm{r}$ weighting in Equation (1). Figure 3.2(b) shows the field derived using $1 / \mathrm{r}^{2}$ weighting. The lengths of the arrows in the fields are proportional to the wind speed at the mode, and the arrows point in the transport direction.

Qualitatively, the wind fields appear nearly equivalent. In both cases, a region of nearly calm wind (short arrows) is found in the vicinity of the Hanford Site; relatively strong southeasterly winds (arrows pointing toward the northwest) are present near Pendleton; relatively strong easterly winds are in the vicinity of Spokane, and northerly winds are along the western edge of the model domain. The primary difference between the wind fields is the size of the low wind speed area near Hanford. The larger low-speed area in Figure 3.2(b) is caused by the additional weight that $1 / r^{2}$ assigns to the HMS wind data in the vicinity of the station. Secondary differences, such as the smoothness of the spatial variations in the wind field, are also noticeable.

Optimal interpolation is a more sophisticated interpolation scheme than the simple distance weighting schemes. This method uses statistical correlations among stations in determining interpolation weights. As a result, optimal interpolation may identify and decrease the influence of unrepresentative observations. However, the statistical aspects of optimal interpolation require substantial analysis of climatological records. As a consequence, the operational mesoscale use of optimal interpolation is quite limited. Although the interpolation scheme has been tested in mesoscale regions by Cats (1980) and Johnson (1982), no use with a transport model is reported. 


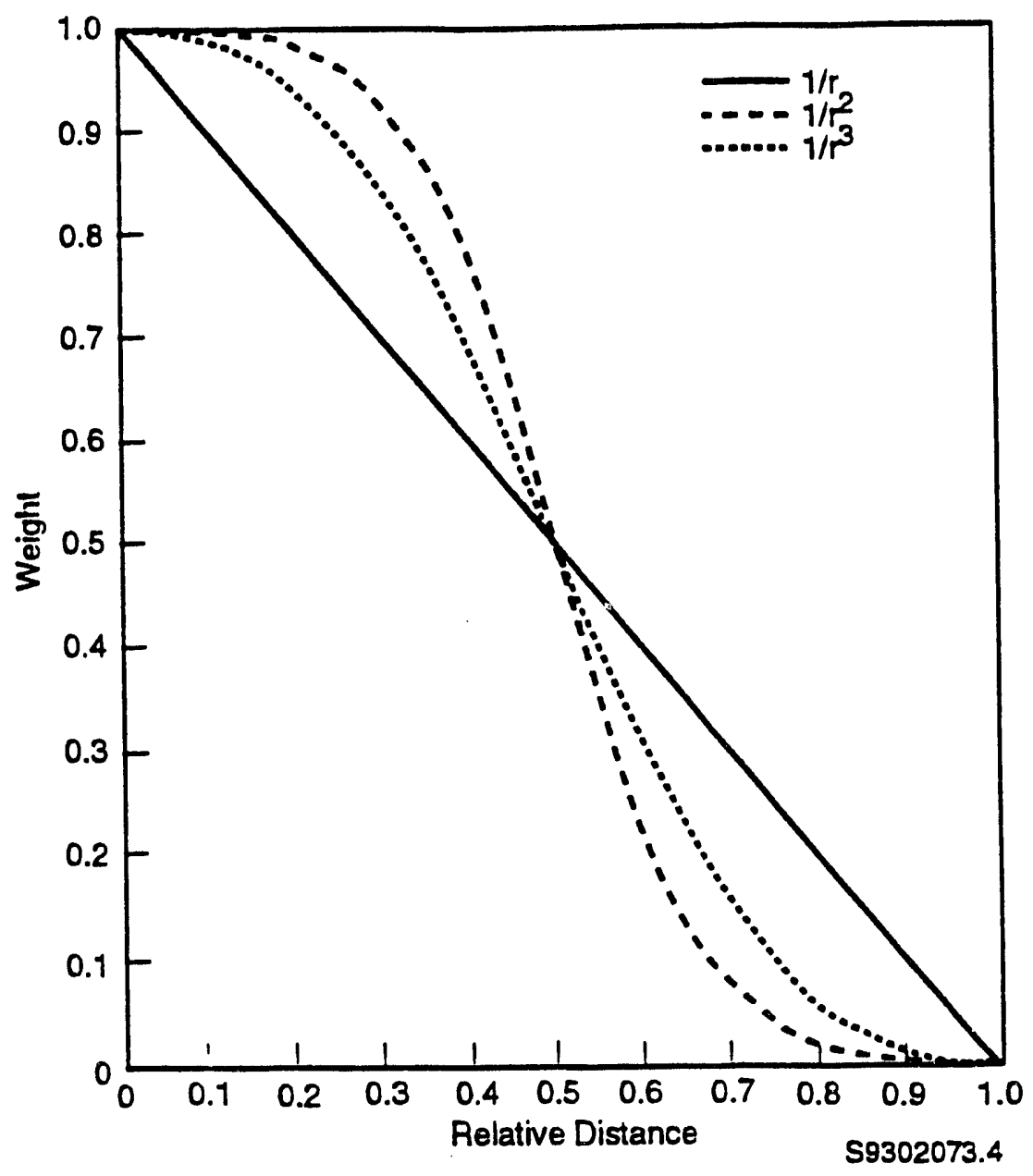

Figure 3.1. Interpolation Variations for Three Weighting Schemes

\subsection{Adjustment Techniques}

Wind fields generated using an interpolation technique are often used directly in transport and diffusion models (such as Ramsdell et al. 1983; Wang and Waldron 1990; Scire et al. 1984). However, other models adjust wind fields to conserve the air mass within the model domain or fit the equations of motion, for example Sherman (1978). Three techniques are commonly used to perform these adjustments: mass consistent methods, transform methods, and data assimilation methods. Transform and data assimilation techniques are computationally too intensive for use in the RATCHET code and are not discussed further in this report. 


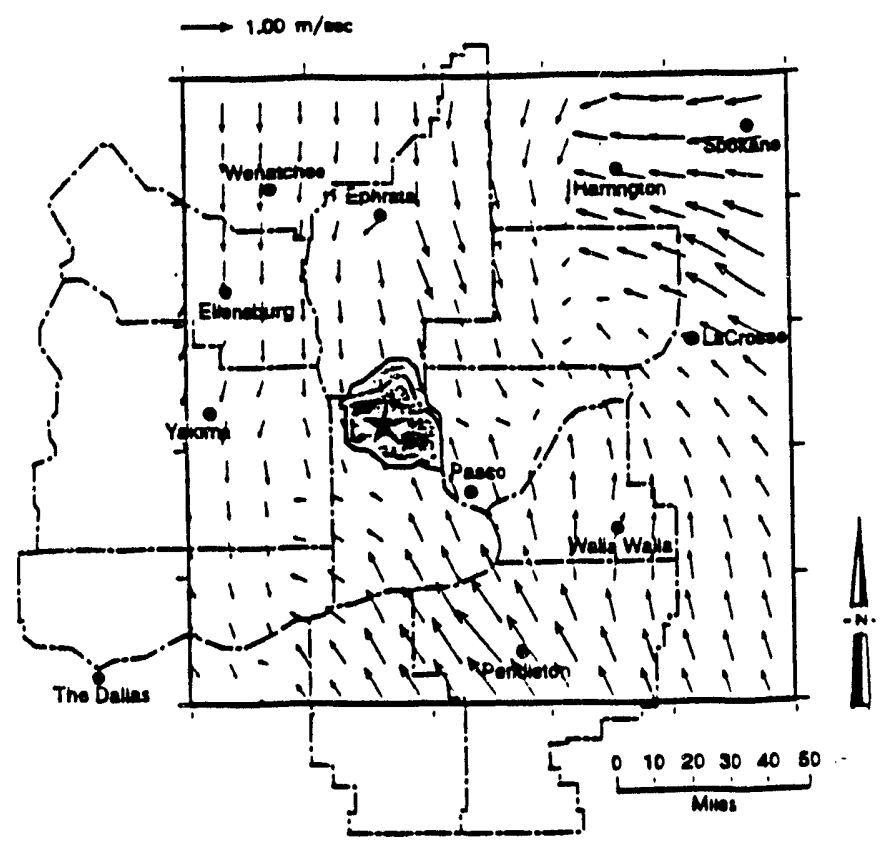

(a) $1 / r$ Interpolation

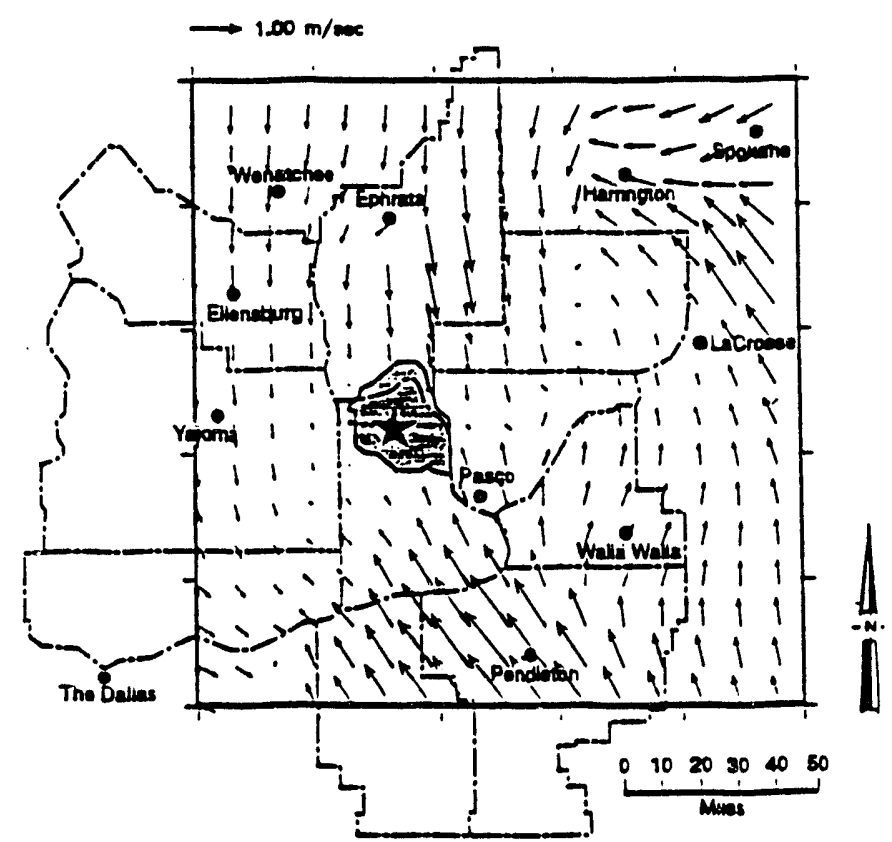

(b) $1 / r^{2}$ Interpolation

Figure 3.2. Comparison of Wind Fields Using Two Weighting Schemes 
One of the first questions raised about wind fields is: are they mass consistent? That is, do they conserve mass? Note this question specifically refers to the mass of air in the model domain. A mass-consistent wind field is one where the continuity equation is satisfied at every point. Assuming that air is an incompressible fluid, the continuity equation is

$$
\frac{\partial u}{\partial x}+\frac{\partial v}{\partial y}+\frac{\partial w}{\partial z}=0
$$

where $u, v$, and $w$ are the wind components and $x, y$, and $z$ are the horizontal coordinates. Diffusion models that compute concentrations using a two-dimensional flux equation require mass-consistent wind fields to conserve the mass of the material being dispersed. This is not an issue in the HEDR Project because RATCHET implements a puff model in which the diffusion and depletion of material are treated independently of its transport method.

However, adjustment of an initial wind field, using a constraint based on the continuity equation, has other potential benefits. For example, adjustment can reduce the effects of small-scale features, such as local terrain or short-lived weather disturbances (for instance, cumulus convection) on an interpolated regional wind field. Such benefits are among the reasons for considering the use of a mass-consistent wind field in RATCHET.

The most popular method for achieving mass consistency is the variational calculus approach originally applied to transport modeling by Sherman (1978). In this technique, an initial gridded wind field is changed by a minimal amount in an overall least squares sense, while assuring continuity of mass or some other dynamical constraint, such as conservation of vorticity. Ross et al. (1988) minimize the equation

$$
E(u, v, w)=\iiint\left\{\alpha_{1}^{2}\left(u-u_{0}\right)^{2}+\alpha_{1}^{2}\left(v-v_{0}\right)^{2}+\alpha_{2}^{2}\left(w-w_{0}\right)^{2}\right\} d v
$$

subject to the mass constraint given in Equation (3). In Equation (4), $V$ is a unit volume, $u_{0}, v_{0}$, and $w_{0}$ are the initial interpolated horizontal and vertical wind components, and $\alpha_{1}$ and $\alpha_{2}$ are coefficients that determine the degree of adjustment of the initial wind field.

Equation (4) represents an estimate of the area-averaged kinetic energy difference between the initial wind field and the nondivergent adjusted wind field. Minimization of this equation ensures that changes to the wind field are made with a minimal impact on overall wind energy. In regions of complex terrain, the solution of Equations (3) and (4) can be affected by terrain features. Sherman (1978) solved the minimization problem by assuming the surface terrain followed a series of steps between grid points. However, this leads to large velocity errors at the surface as shown by Lewellen et al. (1982). More recent implementations use terrain following coordinates that produce a smooth representation of terrain effects (Ross et al. 1988; Traci et al. 1978).

The main difficulty with using mass-consistent adjustment techniques is the number of free parameters that must be empirically or subjectively determined. Minimization of Equation (4) with a 
constraint based on Equation (3) requires a knowledge of the upper-level winds and the mixed-layer height or level of zero vertical motion. Data on upper-level winds are not available for the HEDR atmospheric model domain for the period of interest. As a result, they must be estimated from surface data. The height of the top surface must be estimated, and vertical velocities at the top surface must be specified. In general, vertical velocities at the top surface are not known, and are usually assumed to be zero. In addition, it is necessary to estimate coefficients $\alpha_{1}$ and $\alpha_{2}$ in Equation (4).

The estimates of $\alpha_{2}$ and $\alpha_{1}$ influence the final wind field by controlling relative changes in the wind components. If $\alpha_{1}$ and $\alpha_{2}$ are small, the imposed constraint has a relatively large impact on the final wind field. Conversely, if $\alpha_{1}$ and $\alpha_{2}$ are large, the initial winds are not strongly modified. Finally, the ratio $\alpha_{1} / \alpha_{2}$ determines the relative amount of adjustment of the vertical wind component with respect to the horizontal winds.

The scheme for generating mass consistent wind fields in the NOABL computer code (Traci et al. 1978) was implemented in RATCHET to examine the effects on wind fields and code execution times. The implementation uses three atmospheric layers. It assumed zero initial vertical velocity and a mixed layer height of $1000 \mathrm{~m}(3300 \mathrm{ft})$. The upper-level winds were estimated by the average of the gridded wind components over the model domain.

Figure 3.3 illustrates the effects of $\alpha_{1}$ and $\alpha_{2}$ on wind fields. All three parts of the figure are based on wind data for 2100 PST, December 22, 1944. Figure 3.3(a) shows the initial wind field estimate based on $1 / r^{2}$ interpolation of the data. Figures 3.3(b) and 3.3(c) show wind fields following modification by the NOABL adjustment scheme (Traci et ai. 1978). The only change in the adjustment scheme used for Figures 3.3(b) and 3.3(c) is in the ratio of the parameters $\alpha_{1}$ and $\alpha_{2}$.

An $\alpha_{1} / \alpha_{2}$ ratio of 0.001 , which qualitatively corresponds to unstable atmospheric conditions, was used to generate Figure 3.3(b). The wind directions in this figure show littlc change from the original $1 / \mathrm{r}^{2}$ field. In contrast, in Figure 3.3(c) the $\alpha_{1} / \alpha_{2}$ ratio is 1 , more typical if neutral atmospheric conditions. The result is a noticeable change in wind directions in the southeast portion of the domain. Figures 3.3(b) and 3.3(c) both shorv smoother wind speed transitio is than are seen in Figure 3.3(a). The difference is particularly noticeable in the convergence zone ne ar Pasco.

A variety of simple techniques have been devised to reduce the subjective treatment of the parameters $\alpha_{1}$ and $\alpha_{2}$. For example, Ross et al. (1988) used a simple Froude number approximation to estimate $\alpha_{1} / \alpha_{2}$. This approximation has the effect of including atmospheric stability in the adjustment. Anr,iher approach was tried by Barnard et al. (1987) who modeled flow in a small region (approximately 4 square kilometers) of complex terrain. They used observed wind data to assist in selection of $\alpha_{1} / \alpha_{2}$.

Similarly, a variety of methods have been used to estimate the height of the top surface. King and Bunker (1984) and Goodin et al. (1980) assignod values based on radiosonde observations of the boundary layer structure. Guo and Palutikof (1990) set the top surface using a climatological-based look-up table for night and day. Ultimately, the selection of the top surface depends on the number of observations available for a particular application. When observations are sparse, climatological values can be used with reasonable success. 


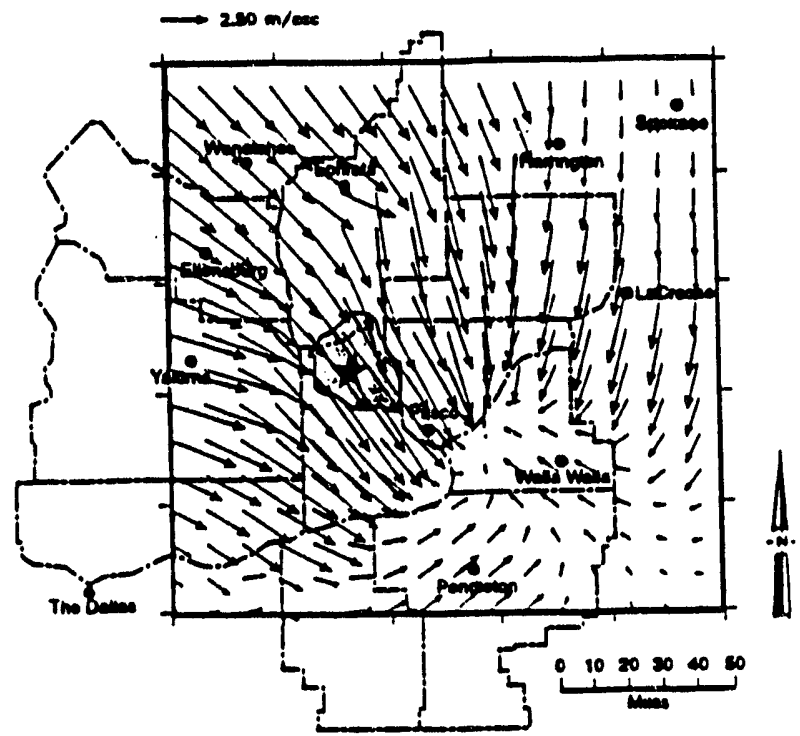

(a) $1 / /^{2}$ Interpolation

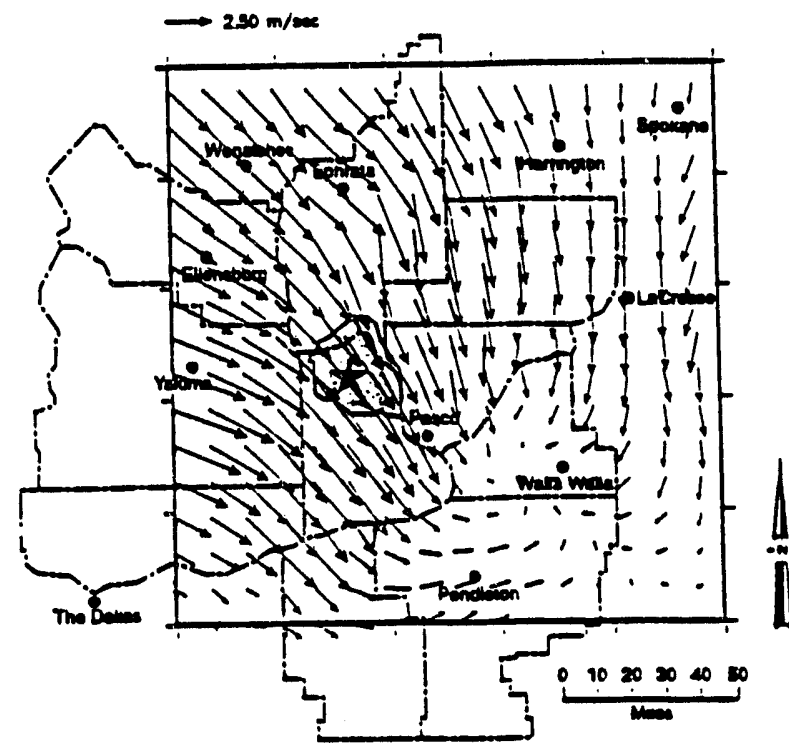

(b) NOABL Unstable $\left(\alpha_{1} / \alpha_{2}=0.001\right)$

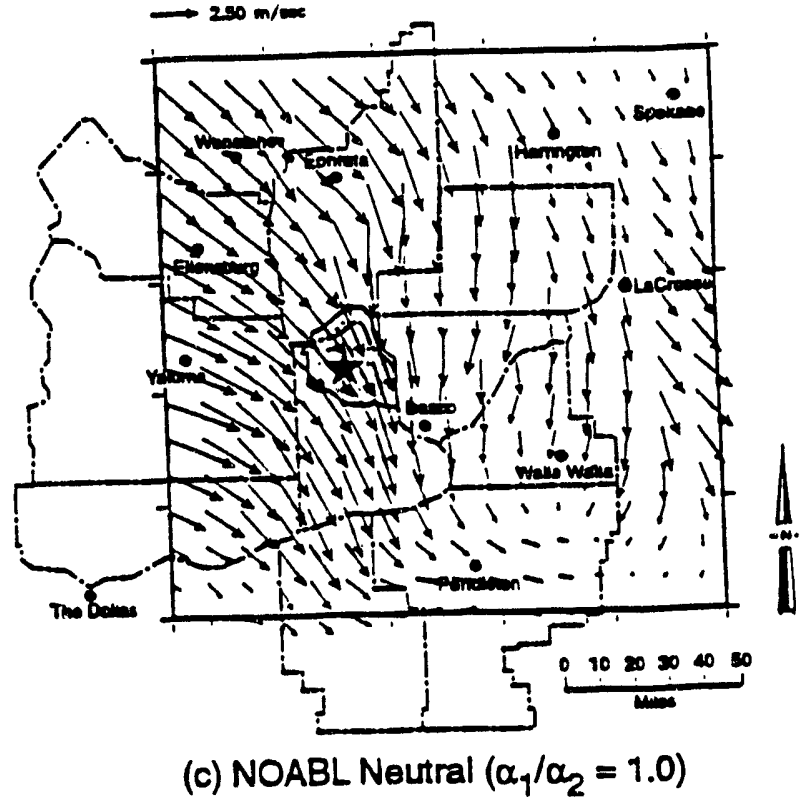

(c) NOABL Neutral $\left(\alpha_{1} / \alpha_{2}=1.0\right)$

Figure 3.3. NOABL Adjustments to Estimated Wind Fields 
One of the significant problems associated with mass consistent techniques is the general lack of model verification for mesoscale applications. Dispersion model comparisons presented by Lewellen and Sykes (1985) and Lewellen et al. (1986) do not show that models using mass-consistent wind fields are better than models using interpolated fields without adjustment. Limited testing is reported in King and Bunker (1984), where the transport and diffusion model described in Davis et al. (1984) is applied at three different locations. Although reasonable model performance is demonstrated, the relative merit of adjusted wind fields over the original interpolated wind fields is not discussed.

Walmsley et al. (1990) compare the results of four complex terrain wind field models to each other and to a reference observation point. Again, the model results show good agreement with the observing stations; however, the number of observation points (three) was too small to test interpolation accuracy. Other model evaluations, such as Mathur and Peters (1990) present resultant fields of vertical motion, which (by definition) should be reduced by the mass consistency requirement. 


\subsection{RATCHET Wind Field Model}

The wind field model in the initial version of RATCHET uses a wind profile to adjust wind speeds to account for height above ground, and $1 / \mathrm{r}^{2}$ interpolation in the horizontal. The model does not account for variations of wind direction with height, and it does not adjust the gridded wind field to achieve mass consistency. Section 3 describes alternative methods for treating winds that could be included in a revised version of RATCHET within the scope of the HEDR Project. This section evaluates the potential changes to the RATCHET wind field model and provides the rationale for the choice of revisions to the RATCHET wind field model. The factors considered in the selection process were

- probable effects of the change on transport rela'ive to the uncertainty in the transport

- probable cost of the change in terms of data requirements and programming difficulty

- probable effect of the change on code execution time.

Uncertainties in the existing wind and source term data discussed in Section 2 provide the reference for use in evaluating changes with respect to the first criterion. Experience gained in developing the initial version of the RATCHET code and in preparing the HEDR meteorological database provide the basis for evaluating changes with respect to the other two criteria.

\subsection{Vertical Extrapolation of Winds}

In RATCHET, vertical extrapolation based on the Monin-Obukhov (1954) similarity theory is used to adjust wind speeds to a standard height prior to interpolating station winds to grid nodes. The similarity profiles are also used to extrapolate gridded winds to plume transport height. In both cases, the wind speed is adjusted, but not the wind direction. The use of similarity profiles for vertical extrapolation of wind within the surface layer was recommended by the working group convened to evaluate model parameterizations for RATCHET (Ramsdell 1992). Nothing has occurred that alters the decision to adopt this recommendation. However, two issues have been raised relative to vertical extrapolation of the wind. The first issue is the height to which the similarity profile can be used, and the other is treatment of changes in wind direction with height. These issues are discussed in Sections 4.2 and 4.3.

\subsection{Profile Model Limitations}

RATCHET limits the use of similarity profiles to the lowest 100 -meter (330-foot) layer in the atmosphere. Under most atmospheric conditions, this limitation is reasonable. However, under extremely stable conditions with a shallow mixing layer, the similarity profiles may not extend to $100 \mathrm{~m}$. ApSimon et al. (1985) assume the wind speed at the top of the boundary layer is twice the

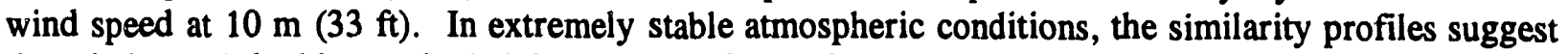
the wind speed doubles as the height increases from $10 \mathrm{~m}$ to $30 \mathrm{~m}(100 \mathrm{ft})$ and the speed at $100 \mathrm{~m}$ 
$(330 \mathrm{ft}$ ) is about four times the speed at $10 \mathrm{~m}$. Limiting the extent of the profile by the ratio of the upper-level wind speed to the 10 -meter wind speed is as arbitrary as limiting the profile to the lowest $100 \mathrm{~m}$ in the atmosphere.

Skibin and Businger (1985) provide a more rational limit to the vertical profile in stable conditions. They show data that indicate departures from the profile are small for heights less than the Monin-Obukhov length and become significant at heights three times the Monin-Obukhov length. The Monin-Obukhov length is a scaling length for heights in the surface layer. It is determined by surface heat flux and a scaling velocity. It can also be estimated from atmospheric stability and surface roughness (Golder 1972). On the basis of the data in the paper by Skibin and Businger, RATCHET will be revised so that the vertical extent of the similarity profile will be limited in stable conditions to the lesser of $100 \mathrm{~m} \mathrm{(330} \mathrm{ft)} \mathrm{or} \mathrm{three} \mathrm{times} \mathrm{the} \mathrm{Monin-Obukhov} \mathrm{length.} \mathrm{This} \mathrm{change} \mathrm{can}$ be implemented in RATCHET with a minor change in the code.

The trcatment of winds at heights above the limit for the similarity profile depends on resolution of issues related to wind directivin shear above the surface leyer. If RATCHET is not changed to estimate upper-level winds from surface meieorological data, the wind speed and direction at heights above the similarity profile limit will continue to be sisumed constant with the values calculated for the limiting height. Estimation of winds above the surface layer is discussed next.

\subsection{Wind Direction Shear}

The second issue related to vertical extrapolation of wirds concerns changes in wind direction with height. In unstable and neutral atmospheric condi.jus, wind direction changes between $10 \mathrm{~m}$

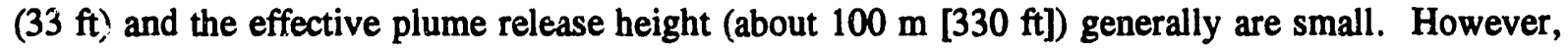
under stable conditions, the turning of wind between $10 \mathrm{~m}$ and $100 \mathrm{~m}$ can be several tens of degrees. In the subsections that follow, two methods of estimating wind directions at heights above $10 \mathrm{~m}$ are evaluated. The first of these methods involves arbitrarily rotating the surface wind direction, and the second involves estimating the surface-level geostrophic wind from sea-level pressures.

\subsubsection{Rotation of the Surface Wind Direction}

The change of wind direction with height is of potential importance in the HEDR Project because its treatment could affect the accuracy of the atmospheric model transport calculations. Theoretical considerations dictate that wind direction in the zorthern hemisphere generally rotates in a clockwise direction as the height above ground increases because the effect of friction decreases. However, this prediction is based on wind flow over horizontally homogeneous terrain in the absence of cold or warm air advection. During stable conditions with a shallow mixing layer, local topographic features may be the dominant factors in determining low-level wind direction, while upper-level wind directions will be determined by large scale weather features. When this occurs, the low-level winds are said to be decoupled from the upper-level flow. The wind direction changes in the lowest $100 \mathrm{~m}$ ( $330 \mathrm{ft}$ ) of the atmosphere may be large, but the low-level winds will not provide any information about the upper winds. Night-time drainage winds, which are common in the Columbia Basin, can cause decsupling of the low-level and upper-level winds. 
Figure 4.1 shows the frequency distribution of differences in wind direction between $15 \mathrm{~m}$ $(50 \mathrm{ft})$ and $61 \mathrm{~m}(200 \mathrm{ft})$ on the HMS tower from 1982 through 1991. When comparing Figure 4.1 with the 1-hour lag curve in Figure 2.1, it is clear the differences in direction between 15 and $61 \mathrm{~m}$ are generally smaller than the differences in direction between consecutive hours. The standard deviation of the differences in the distribution shown in Figure 4.1 is $22.6^{\circ}$. About 37 percent of the time the wind directions at the twi levels are in the same 10-degree sector; and, more than 70 percent of the time, the upper direction is in a 30-degree sector centered on the sector containing the lower direction.

Another feature of interest in Figure 4.1 is the noticeable skew in the frequency distribution. The difference in direccions is more likely positive ( 46.0 percent) than negative ( 16.6 percent). This clockwise rotation of the wind direction with increasing height is consistent with the rotation predicted by the geostrophic and gradient wind equations. However, note that counterclockwise rotation of the wind with height is not rare. This situation argues against applying an arbitrary direction rotation to account for changes in wind direction with height.

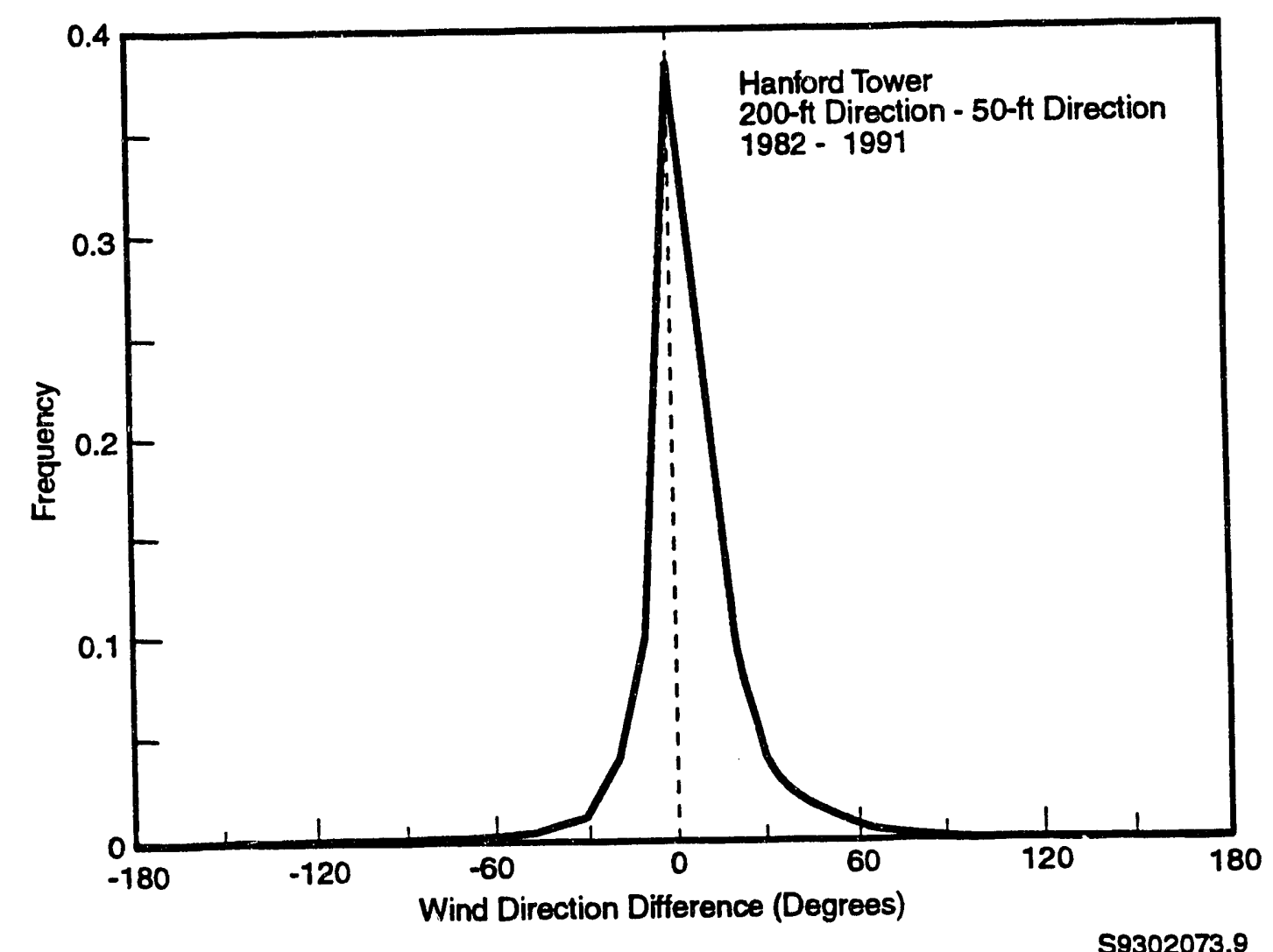

Figure 4.1. Freqiency of Wind Direction Differences Between Two HMS Tower Levels 
The effects of topography on wind, for example, due to channeling or temperature gradients, are ignored in the theoretical relationships between lower- and upper-level winds. The effects of thermal advection can be incorporated in the theoretical relationships. However, implementation of a procedure for estimating the effects of thermal advection would involve developing a meteorological model that goes well beyond the meteorological models found in other simple dispersion codes. Developing such a model and entering the data to support this model would exceed the currently approved scope of the HEDR Project.

Low wind speed, stable conditions are likely to be associated with the largest changes in wind direction with height. When these conditions occur, the effects of local topography can have more influence over low-level directions than the pressure gradient. To estimate the upper-level wind from low-level data at these times would require site specific correction factors that account for topography. Such correction factors are not available; a significant research effort would be required to estimate them from available data. An effort of the required magnitude is beyond the currently approved scope of the HEDR Project.

\subsubsection{Geostrophic Wind from Pressure Data}

The second alternative considered for estimating upper-level winds is direct calculation from surface pressures. Upper winds computed from pressures reported in and near the HEDR atmospheric model domain would be subject to larger errors than described by Sykes and Hatton (1976). Sykes and Hatton do not consider the potential errors involved in adjusting station pressures to sea level because they deal primarily with data from stations near sea level. This section discusses this source of errors.

Changes of pressure with height are much larger than horizontal pressure changes. Therefore, the observed pressures must be adjusted to a standard height before the pressure gradients needed to estimate upper-level winds can be calculated. Mean sea level has been chosen as the standard height. Hess (1959, pp. 88-91), Wallace and Hobbs (1977, pp. 59-60), and Saucier (1955, pp. 56-58) describe the method of reduction of station pressures to sea level. The adjustment, which requires an estimate of the mean virtual temperature in the fictitious layer of air between the measurement height and sea level, is approximately 1 millibar $(\mathrm{mb})(1013.2 \mathrm{mb}=29.92$ inches of water) for each $8 \mathrm{~m}$ $(26 \mathrm{ft}$ ) above sea level. Typical adjustments within the HEDR domain range from about $10 \mathrm{mb}$ at the Dallesport meteorological station to about $150 \mathrm{mb}$ at the Stampede Pass meteorological station.

Virtual temperature is the temperature of dry air that, at a given pressure, has the same air density as moist air. The difference between the observed temperature and the virtual temperature depends on the amount of moisture in the air. Errors in estimating the mean virtual temperature cause errors in sea-level pressure estimates. The magnitude of the errors in sea-level pressure depends on station elevation and, to a lesser extent, on temperature. Many of the meteorological stations in the HEDR domain have elevations of about $400 \mathrm{~m}$ (1300 ft). Changing virtual temperatures for stations at this elevation by $1^{\circ} \mathrm{C}\left(1.8^{\circ} \mathrm{F}\right)$ changes the sea-level pressure estimate by $0.1 \mathrm{mb}$. As a first approximation, the ratio between the change in virtual temperature and the change in sea-level pressure is directly proportional to the station elevation. Thus, a $1^{\circ} \mathrm{C}$ error in virtual 
temperature at the Stampede Pass station leads to about a $0.3-\mathrm{mb}$ error in sea-level pressure. The same error in virtual temperature at the Ellensburg or Spokane stations leads to an error of $0.2 \mathrm{mb}$ in surface pressure.

The texts by Hess (1959) and Wallace and Hobbs (1977) both characterize the process of reduction of station pressures to sea level as unsatisfactory for mountainous areas. Saucier (1955) states the reduction procedures used are different for stations with elevations above and below $305 \mathrm{~m}$ $(1000 \mathrm{ft})$. He states that differences in sea-level pressures for neighboring stations, one with an elevation above and the other with an elevation below $305 \mathrm{~m}(1000 \mathrm{ft})$, may be approximately $0.5 \mathrm{mb}$. Saucier also discusses (p. 64) the impact of local station temperatures on estimates of sealevel pressure. He suggests that sea-level pressure patterns are a product of both true horizontal pressure variations and local surface temperature effects that may not be related to the surface pressure.

The geostrophic wind is calculated from sea-level pressure gradients. These gradients are approximated from sea-level pressure differences. Changing a sea-level pressure difference over a distance of $100 \mathrm{~km}(62 \mathrm{mi})$ by $0.1 \mathrm{mb}$ causes a change in the geostrophic wind components by more than $1 \mathrm{~m} / \mathrm{sec}(2.2 \mathrm{mph})$. Errors in pressure differences may be larger than errors in the sea-level pressure estimates because pressure differences are computed from pressures that may have errors of opposite signs. Therefore, errors in estimates of the geostrophic wind components can be several meters per second, even if suitable data are available for the computations.

Atmospheric pressure data are generally available for the same meteorological stations that have wind data. However, HEDR meteorological data files do not include pressure data. These data could be added to the station files with additional data entry. Unfortunately, pressure data are not available for the HMS prior to 1953. Some stations, such as Pasco, Moses Lake, and Lewiston, have only limited value for determining pressure fields because of their periods of record. In addition, potential topographic effects on station pressure and uncertainty in reduction of station pressure to sea-level decreases the value of data from other stations, such as Stampede Pass, Dallesport, Yakima, and Wenatchee. Nevertheless, sufficient pressure data exist for estimating geostrophic winds over the HEDR model domain.

The RATCHET code does not make use of geostrophic winds; the code revision needed to make use of geostrophic winds would be a modest effort. Changes would be required in the data input format and in the calculation of puff movement in addition to the changes related to calculation of the geostrophic wind field. However, direction changes between the surface wind and the geostrophic wind are generally less than $45^{\circ}$. The uncertainties in the wind directions during release already included in RATCHET are larger than the changes in wind direction in the lower atmosphere.

Carhart et al. (1989) describe a comparison of dispersion model transport predictions with experimental data. A model that relied only on surface wind directions predicted plume positions within 10 to $20^{\circ}$ of the actual plume positions 50 percent more frequently than any other model. A model that used only upper-level winds predicted correct plume directions least frequently. Most of the models in the study showed a tendency to predict plume positions that were rotated clockwise from the observed plume positions (when viewed from above). The model that used only surface wind directions did not show this tendency. 
The value of adding geostrophic wind data to the RATCHET code is considered to be marginal. Addition of pressure data to the meteorological database cannot be accomplished within the current budget and schedule. As a result, calculation and use of the geostrophic wind will not be added to RATCHET.

\subsubsection{Estimating Direction Shear from HMS Tower Data}

Neither the use of an arbitrary rotation angle nor the calculation of the surface geostrophic wind appears to be a practical method for estimating upper-level wind directions. However, there is a third alternative that is viable. Since December 1944, wind directions have been reported for the 50 -foot, 200-foot, and 400-foot levels of the HMS tower. These wind direction data provide some information on direction shear near the stacks where most of the iodine-131 was released to the atmosphere.

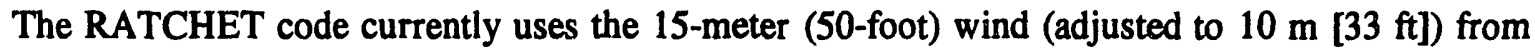
the HMS in the wind field interpolation. Figure 4.1 clearly shows frequent and, in the long term, systematic differences between the wind directions at 15 and $61 \mathrm{~m} \mathrm{(50}$ and $200 \mathrm{ft})$. The 61 -meter wind is at the same height as releases from the $B$ and $T$ separation plants at Hanford. Therefore, the RATCHET code will be modified to use the 61 -meter wind (adjusted to $10 \mathrm{~m}$ ) in preparation of the wind field. This change can make use of the direction information at release height without resorting to arbitrary assumptions. A minor modification of the computer code is all that is required to make the change.

The largest differences in wind directions between 15 and $61 \mathrm{~m} \mathrm{(50} \mathrm{and} 200 \mathrm{ft}$ ) at the HMS occur during stable conditions when topography, such as Rattlesnake Mountain, influences the lowlevel winds the most. Under these conditions, local topographic features near other sites may influence the winds at those sites differently than topographic features near HMS affect the wind there. As a result, it is inappropriate to use HMS wind direction shear data throughout the HEDR model domain.

\subsection{Horizontal Interpolation of Winds}

Various methods have been developed for interpolating winds from randomly spaced observation points to evenly spaced nodes on a grid. Several of these methods are described in Section 3.1.2. RATCHET uses weighted interpolation with $1 / r^{2}$ weighting. This is one of the common, if not the most common, methods of weighting. No other single interpolation method has replaced the $1 / \mathrm{r}^{2}$ weighted averaging method in common usage.

Differences among hourly wind fields that result from differences in interpolation methods are generally small. Figure 3.2 shows an example of changes resulting from weighting. The HEDRIC system of codes accounts for uncertainties in release times that typically are about eight hours. The changes in wind fields associated with passing weather systems and diurnal thermal effects over this period are larger than the differences in wind fields associated with interpolation methods. Therefore, RATCHET will continue to use $1 / \mathrm{r}^{2}$ weighted averaging for horizontal interpolation of winds. 


\subsection{Wind Field Adjustments}

The review of wind field adjustment techniques in Section 3.2 indicates that, for the period of interest, the techniques usually require more information than is readily available for the HEDR atmospheric model domain. Undocumented experiences with a wind field model based on the code of Allwine and Whiteman (1985) indicate the use of transform methods for wind field calculation requires more time than can reasonably be allotted for RATCHET wind field calculations. Data assimilation techniques for adjusting wind fields were dismissed from consideration for the same reason. For example, a typical 24-hour model run requires roughly 53 minutes of Cray XMP computer time (Gaei et al. 1988). Design specifications for the RATCHET code (Ramsdell and Burk 1992, p. 4.1) established a goal for RATCHET execution of no more than 1 second per hour of real time simulation.

For evaluation purposes, two mass consistent wind field adjustment algorithms (Traci et al. 1978; Mathur and Peters 1990) have been implemented in modified versions of RATCHET. These algorithms use different methods of wind field adjustment. Under most conditions, the differences among the initial wind fields generated by $1 / \mathrm{r}^{2}$ weighted averaging and the adjusted fields are small. See Figure 3.3(c) for an example of relatively large changes. However, significant differences are found in the time required for program execution. When the wind field adjustment algorithm proposed by Mathur and Peters is used, RATCHET execution takes more than twice as long as execution with only $1 / \mathrm{r}^{2}$ interpolation. The algorithm proposed by Traci et al. (1978) increases RATCHET execution time by nearly a factor of three.

Recent calculations with the RATCHET code indicate execution speed design criteria can be met even when using a mass consistent wind field adjustment algorithm. The question then becomes whether sufficient value is added by the mass consistent algorithm to justify the additional computational time.

Dispersion model evaluations involving short releases have failed to find that models using wind fields adjusted for mass consistency produce better concentration predictions than models that use interpolated wind fields without adjustment (Lewellen et al. 1982; Lewellen and Sykes 1985; Lewellen et al. 1986; Weber et al. 1987; Klug et al. 1992). Reports by Weber et al. (1982) and Carhart et al. (1989) suggest that correct treatment of wind fields is less important in estimating longterm concentrations than in estimating short-term concentrations.

Mass consistent wind fields do not have demonstrable value in estimating short-term concentrations. Given the uncertainties in model input, the relatively small range of time-integrated air concentrations calculated for 1945 (Table 2.1) indicate that mass consistent wind fields would be of even less value in estimating long-term concentrations than in estimating short-term concentrations. Unless future model evaluation studies offer positive evidence that additional computational time required to adjust wind fields for mass consistency improves model performance in predicting concentrations, this additional computational time is not warranted in RATCHET. Therefore, RATCHET will not include a mass-consistent wind field adjustment algorithm. RATCHET will continue to use the initial interpolated wind fields for transport calculations. 


\subsection{Conclusions}

The RATCHET computer code has been developed to make atmospheric transport and diffusion calculations for the HEDR Project. The initial version of the code uses surface wind data and simple interpolation methods to transform observed wind data into wind fields for use in transport calculations. RATCHET demonstrated that required calculations can be completed in a timely manner and can produce results consistent with those of previous studies. The code is undergoing review to determine its final form. This report describes and evaluates procedures for transforming wind data into wind fields and provides rationale for revision of the procedures used in the initial version of RATCHET.

Section 2 of the report describes the nature of the uncertainties in the input data used by the RATCHET code in calculation of time-integrated air concentrations and surface contamination. It also presents a preliminary characterization of the variability in the output of the code. This information is used in Section 4 to evaluate the various aspects of computing wind fields for use in atmospheric transport calculations. This section of the report summarizes the conclusions reached in Sections 2 and 4.

\subsection{Uncertainty in Model Input and Variability in Model Output}

Uncertainties associated with instrument performance at low wind speeds and the representativeness of 1-minute observations are discussed in Section 2. Imprecision of the recorded wind data results in a basic uncertainty of $\pm 11.25^{\circ}$ in wind directions and $\pm 0.5 \mathrm{kn}$ for all meteorological stations except HMS. The uncertainty in wind speed for the HMS due to imprecision is $\pm 0.5 \mathrm{mph}$. This uncertainty is treated in the initial version of RATCHET. A procedure will be added to RATCHET to treat additional uncertainty associated with diminished instrument accuracy at low wind speeds.

The potential errors associated with use of 1-minute observations were evaluated by comparing the differences in wind directions observed in consecutive hours with differences in observed wind directions when the observations were $8 \mathrm{hrs}$ apart. The uncertainty in release times was on the order of $8 \mathrm{hrs}$. This comparison indicates that direction uncertainty associated with uncertainty in release times is significantly larger than the uncertainty in the use of 1-minute observations.

Results of calculations made with the initial version of RATCHET show that large uncertainties in the hourly release rates and the imprecision in station winds do not result in large variations of annual time-integrated air concentrations between model realizations. Over time, the integration performed by the model filters out most of the variability in model input. It is reasonable to interpret this result as indicating that climatological patterns are more important for estimating dispersion of continuing long-term releases than individual hourly patterns. Therefore, no attempt will be made to revise RATCHET to account for the uncertainties associated with the 1-minute meteorological observation period used at all stations except the HMS. 


\subsection{Boundary Layer Wind Profile}

The use of similarity profiles for vertical extrapolation of wind within the surface layer was recommended by the working group convened to evaluate model parameterizations for RATCHET (Ramsdell 1992). Nothing has occurred or been found that would alter the decision to adopt this recommendation. In the initial version of RATCHET, use of the profile was limited to the lower $100 \mathrm{~m}(330 \mathrm{ft})$ of the atmosphere. In the revised version of the code, use of the similarity profile should be limited in stable conditions to the lesser of $100 \mathrm{~m}$ (330 ft) or 3 times the Monin-Obukhov length.

\subsection{Wind Direction Shear}

The initial version of the RATCHET code assumed that wind direction is independent of the height above ground. This assumption is not correct. However, evaluation of several transport models by Carhart et al. (1989) indicate that models relying on surface wind data can perform as well as, or better than, models that use upper-air wind data.

Section 4 includes an evaluation of two methods for estimating the change in wind direction with height. One method involves use of an arbitrary rotation of the wind direction with height, and the other involves the use of surface level pressures to estimate the geostrophic wind. Neither method is appropriate for incorporation during revision of RATCHET. Errors associated with simple rotation of the wind are likely to be as large as the errors associated with assuming the wind direction is independent of height, and the potential costs of developing more complex procedures would exceed TSP-directed scope for the HEDR Project. The alternative, using pressure data, is rejected for similar reasons.

Wind direction data from the HMS tower do, on occasion, show significant direction differences between the 50-foot and 200-foot heights on the tower. The 200-foot level corresponds to the release height for radionuclides (such as iodine-131) from the fuel separation plants. Therefore, the RATCHET code will be modified to use the 61 -mile wind (adjusted to $10 \mathrm{~m}$ ) in the preparation of the wind field. This change will make use of the directional information at release height without resorting to arbitrary assumptions.

The largest differences in directions occur under meteorological conditions where local topographic effects on wind direction are the greatest. Topographical influences on wind direction are specific to the measurement locale. Therefore, the wind direction shear data from HMS will not be applied universally throughout the HEDR model domain.

\subsection{Horizontal Interpolation}

The HEDRIC system of codes accounts for uncertainties in release times that are about eight hours. The changes in wind fields associated with passing weather systems and diurnal thermal 
effects over this period are larger than the differences in wind fields associated with interpolation methods. Therefore, RATCHET will continue to use $1 / \mathrm{r}^{2}$ weighted averaging for horizontal interpolation of winds.

\subsection{Mass Consistent Wind Field Adjustments}

The initial version of RATCHET uses wind fields generated by interpolation and extrapolation for transport calculations. Methods for adjusting these wind fields to achieve mass consistency are described and evaluated in Sections 3 and 4, respectively. Dispersion model evaluations involving short releases have failed to demonstrate that models using wind fields adjusted for mass-consistency produce better concentration predictions than models that use interpolated wind fields without adjustment. Other studies suggest that correct treatment of wind fields is less important in estimating long-term concentrations than it is in estimating short-term concentrations. A mass consistent wind field is not required to ensure the conservation of the other mass of radionuclides within the RATCHET code. Tests of two mass-consistent adjustment schemes in a modified version of RATCHET indicate that they more than double the computational time required for the model. Therefore, RATCHET will continue to use interpolated wind fields for transport calculations.

\subsection{RATCHET Status}

Alternative methods of treating wind data have been evaluated for possible implementation in the version of RATCHET to be used for HEDR Project dose calculations. The alternatives considered range from methods included in models that are similar in complexity to RATCHET to methods that are included in much more sophisticated models. Several changes will be made in the treatment of wind data in RATCHET as a result of information uncovered in this review. When these code revisions are complete, RATCHET will be ready for final code tests and model evaluation. No experimental evidence shows that further increases in the complexity of the RATCHET would improve its ability to estimate the transport of radionuclides released to the atmosphere from Hanford operations. 


\subsection{References}

Allwine, K. J. and C. D. Whiteman. 1985. MELSAR: A Mesoscale Air Quality Model for Complex Terrain. PNL-5460, Pacific Northwest Laboratory, Richland, Washington.

Andres, A. 1990. "A Meso-Scale Plume Dispersion Model. Preliminary Evaluation in a Heterogeneous Area." Atmospheric Environment, 24A(4):883-896.

ApSimon, H. M., A. J. H. Goddard, and J. Wrigley. 1985. "Long-Range Atmospheric Dispersion of Radioisotopes-I. The MESOS model." Atmospheric Environment, 19(1):99-111.

Barnard, J. C., H. L. Wegley, and T. R. Hiester. 1987. "Improving the Performance of MassConsistent Numerical Models Using Optimization Techniques". Journal of Climate and Applied Meteorology, 26(6):675-686.

Carhart, R. A., A. J. Policastro, M. Wastag, and L. Coke. 1989. "Evaluation of Eight Short-Term Long-Range Transport Models Using Field Data." Atmospheric Environment. 23(1):85-105.

Cats, G. J. 1980. "Analysis of Surface Wind and Its Gradient in a Mesoscale Wind Observation Network." Monthly Weather Review, 108(8):1100-1107.

Davis, C. G., S. S. Bunker, and J. P. Mutschlecner. 1984. "Atmospheric Transport Mndels for Complex Terrain." Journal of Climate and Applied Meteorology, 23(2):235-238.

Gaei P., S. Perdriel, and J. Y. Caneill. 1988. "Assessing the Transport-Diffusion of Effluents at Mesoscale: An Application to the Rhone River Valley Area." Eighth Symposium on Turbulence and Diffusion, American Meteorological Society, Boston, Maine, 232-235.

Golder, D. 1972. "Relations Among Stability Parameters in the Surface Layer." Boundary Layer Meteorology, 3(1):47-58.

Goodin, W. R., G. J. McRae, and J. H. Seinfeld. 1979. "A Comparison of Interpolation Methods for Sparse Data: Application to Wind and Concentration Fields." Journal of Applied Meteorology, 18(6):761-771.

Goodin, W. R., G. J. McRae, and J. H. Seinfeld. 1980. "An Objective Analysis Technique for Constructing Three-Dimensional Urban-Scale Wind Fields." Journal of Applied Meteorology, 19(1):98-118.

Guo, X. and J. P. Palutikof. 1990. "A Study of Two Mass-Consistent Models: Problems and Possible Solutions." Boundary-Layer Meteorology, 53(4):303-332.

Heeb, C. M. 1993. Iodine-131 Releases from the Hanford Site, 1944 through 1947. PNWD-2033 HEDR Vol. 1, Battelle, Pacific Northwest Laboratories, Richland, Washington. 
Hess, S. L. 1959. Introduction to Theoretical Meteorology. Holt, New York. 362 p.

Hilst, G. R. 1951a. The Determination of Probable Trajectories for Airborne Wastes Emitted in the Hanford Works Area Report Number One January, 1951. HW-20502, General Electric Company, Hanford Works, Richland, Washington.

Hilst, G. R. 1951b. Probable Trajectories for Hypothetical Airborne Wastes Emitted in the Hanford Works Area During March, April, and May, 1951. HW-21414, General Electric Company, Hanford Works, Richland, Washington.

Ikenberry, T. A., R. A. Burnett, B. A. Napier, N. A. Reitz, and D. B. Shipler. 1992. Integrated Codes for Estimating Environmental Accumulation and Individual Dose from Past Hanford

Atmospheric Releases. PNL-7993 HEDR. Pacific Northwest Laboratory, Richland, Washington.

Johnson, G. 'T. 1982. "Climatological Interpolation Functions for Mesoscale Wind Fields." Journal of Applied Meteorology, 21(8):1130-1136.

King, D. S. and S. S. Bunker. 1984. "Application of Atmospheric Transport Models for Complex Terrain." Journal of Climate and Applied Meteorology, 23(2):239-246.

Klug, W., G. Graziani, G. Grippa, D. Pierce, and C. Tassone. 1992. Evaluation of Long Range Atmospheric Transport Models Using Environmental Radioactivity Data from the Chernobyl Accident. Elsevier Applied Science, London. 366 p.

Lamb, R. G. and S. K. Hati. 1987. "The Representation of Atmospheric Motion in Models of Regional-Scale Air Pollution." Journal of Climate and Applied Meteorology, 26(7):837-846.

Lewellen, W. S., R. I. Sykes, C. P. Cerasoli, and F. C. Kornegay. 1986. Comparison of the 1982 SEADEX Dispersion Data with Results from a Number of Different Models, NUREG/CR-4820, U.S. Nuclear Regulatory Commission, Washington, D.C.

Lewellen, W. S. and R. I. Sykes. 1985. A Scientific Critique of Available Models for Real-Time Simulations of Dispersion. NUREG/CR-4157, U.S. Nuclear Regulatory Commission, Washington, D.C.

Lewellen, W. S., R. I. Sykes, and D. Oliver. 1982. The Evaluation of MATHEW/ADPIC as a RealTime Dispersion Model. NUREG/CR-2199, U.S. Nuclear Regulatory Commission, Washington, D.C.

Mathur, R. and L. K. Peters. 1990. "Adjustment of Wind Fields for Application in Air Pollution Modeling." Atmospheric Environment, 24A(5):1095-1106.

Meyer, S. L. 1975. Data Analysis for Scientists and Engineers. John Wiley \& Sons, New York. $513 \mathrm{p}$. 
Monin, A. S. and A. M. Obukhov. 1954. "Basic Laws of Turbulent Mixing in the Ground Layer of the Atmosphere." Trans Geophys Imot. Akad, Nauk, USSR, 151:260-263.

Nickola, P. W. 1951. Probable Trajectories for Hypothetical Airborne Wastes Emitted in the Hanford Works Area During June, July, and August 1951. HW-22470, General Electric Company, Hanford Works, Richland, Washington.

Nickola, P. W. 1952. Probable Trajectories for Hypothetical Airborne Wastes Emitted in the Hanford Works Area During September, October, and November, 1951. HW-23601, General Electric Company, Hanford Works, Richland, Washington.

Nickola, P. W. 1953. Probable Trajectories for Hypothetical Airborne Wastes Emitted in the Hanford Works Area During December 1951, and January, February, and March, 1952. HW-27172, General Electric Company, Hanford Works, Richland, Washington.

Panofsky, H. A., and J. A. Dutton. 1984. Atmospheric Turbulence. Wiley-Interscience, New York. 398 p.

Pielke, R. A. 1989. Status of Mesoscale and Subregional Models: Volume 2. Mesoscale Meteorological Models in the United States. Report No. EPRI-EN-6649, October, Electric Power Research Institute, Palo Alto, California.

Pollard, J. H. 1977. A Handbook of Numerical and Statistical Techniques. Cambridge University Press, Cambridge, Massachusetts. 349 p.

Ramsdell, J. V. 1992. Summary of the March 25-26, 1991 Atmospheric Model Working Meeting, PNWD-1975 HEDR, Battelle, Pacific Northwest Laboratories, Richland, Washington.

Ramsdell, J. V. and K. W. Burk. 1992. Regional Atmospheric Transport Code for Hanford Emission Tracking (RATCHET), PNL-8003 HEDR, Pacific Northwest Laboratory, Richland, Washington.

Ramsdell, J. V., G. F. Athey, and C. S. Glantz. 1983. MESOI Version 2.0: An Interactive Mesoscale Lagrangian Puff Dispersion Model with Deposition and Decay, NUREG/CR-3344, U.S. Nuclear Regulatory Commission, Washington, D.C.

Ross, D. G., I. N. Smith, P. C. Manins, and D. G. Fox. 1988. "Diagnostic Wind Field Modeling for Complex Terrain: Model Development and Testing." Journal of Applied Meteorology, 27(7):785-796.

Saucier, W. J. 1955. Principles of Meteorological Analysis. University of Chicago Press, Chicago. $438 \mathrm{p}$.

Schere, K. L. and C. J. Coates. 1992. "A Stochastic Methodology for Regional Wind-Field Modeling." Journal of Applied Meteorology, 31(12):1407-1425. 
Scire, J. S., F. W. Lurmann, A. Bass, and S. R. Hanna. 1984. User's Guide to the MESOPUFF II Model and Related Processor Programs. EPA Report No. EPA-600/8-84-013.

Sherman, C. A. 1978. "A Mass-Consistent Model for Wind Fields Over Complex Terrain." Journal of Applied Meteorology, 17(3):312-319.

Shipler, D. B. 1993. Integrated Task Plans for the Hanford Environmental Dose Reconstruction Project, FY 1992 through May 1994. PNWD-2020 HEDR, Battelle, Pacific Northwest Laboratories, Richland, Washington.

Skibin, D. and J. A. Businger. 1985. "The Vertical Extent of the Log-Linear Wind Profile Under Stable Stratification." Atmospheric Environment, 19(1):27-30.

Stage, S. A., J. V. Ramsdell, C. A. Simonen, and K. W. Burk. 1993. Interim Report on the Meteorological Database. PNWD-2090 HEDR. Battelle, Pacific Northwest Laboratories, Richland, Washington.

Stull, R. B. 1988. An Introduction to Boundary Layer Meteorology. Kluwer Academic Publishers, Dordrect, Netherlands.

Sykes, R. I. and L. Hatton. 1976. "Computation of Horizontal Trajectories Based on the Surface Geostrophic Wind." Atmospheric Environment, 10(1):925-934.

Traci, R. M., G. T. Phillips, P. C. Patnaik. 1978. Developing a Site Selection Methodology for Wind Energy Conversion Systems. DOE Report No. DOE/ET/20280-3, Science Applications, Inc., La Jolla, California.

Wallace, J. M. and P. V. Hobbs. 1977. Atmospheric Science: An Introductory Survey. Academic Press, New York, 467 p.

Walmsley, J. L., I. Troen, D. P. Lalas, and P. J. Mason. 1990. "Surface-Layer Flow in Complex Terrain: Comparison of Models and Full-Scale Observations." Boundary-Layer Meteorology, 52(3):259-281.

Wang, I-T and T. L. Waldron. 1990. User's Guide for MTDDIS Mesoscale Transport, Diffusions, and Deposition Model for Industrial Sources. ABB Environmental Services, Inc., Camarillo, California.

Weber, A. H., M. R. Buckner, and J. H. Weber. 1982. "Statistical Performance of Several Mesoscale Atmospheric Dispersion Models." Journal of Applied Meteorology, 21(11):1633-1644.

Wendell, L. L. 1972. "Mesoscale Wind Fields and Transport Estimates Determined From a Network of Towers," Monthly Weather Review, 100(4):565-578. 
Yamada, T. and S. Bunker. 1988. "Development of a Nested Grid, Second Moment Turbulence Closure Model and Application to the 1982 ASCOT Brush Creek Data Simulation," Journal of Applied Meteorology, 27(5):562-578. 


\section{Distribution}

No. of

Copies

\section{OFFSITE}

Technical Steering Panel

D. S. Barth

University of Nevada

4505 Maryland Parkway

Las Vegas, NV 89154

W. A. Bishop

2503 Wedgewood Court S.E.

Olympia, WA 98501

M. L. Blazek

Oregon Department of Energy

625 Marion Street N.E.

Salem, OR 97310

G. G. Caldwell

Tulsa City-County Health Dept. 4616 East 15th Street

Tulsa, OK 74112

S. N. Davis

Dept. of Hydrology and Water

Resources

Building 11

University of Arizona

Tycson, AZ 85721

N. J. Germond

224 Iron Mountain Blvd.

Lake Oswego, OR 97.034

P. C. Klingeman

Civil Engineering Dept.

Apperson Hall 202

Oregon State University

Corvallis, OR 97331-2302
No. of

Copies

K. J. Kopecl.y

Fred Hutchinson Cancer Research

Center

1124 Columbia Street

Seattle, WA 98104

P. D. McGavran

Dept. of Health and Welfare

450 W. State Street, 4th Floor

Boise, ID 83720-5450

R. L. Morrill

Dept. of Geography, DP-10

University of Washington

Seattle, WA 98195

A. H. Murphy

3115 NW McKinley Drive

Corvallis, OR 97330

D. W. Price

Agricultural Economics

Hulbert Hall Room 211

Washington State University

Pullman, WA 99164-6210

M. A. Robkin

Radiological Sciences, SB-75

University of Washington

Seattle, WA 98195

G. S. Roessler

Route 1, Box 139H

Elysian, MN 56028

B. Shleien

2421 Homestead Drive

Silver Springs, MD 20902

Distr. 1 
No. of

Copies

A. P. Slickpoo, Sr.

$809 \mathrm{Nez}$ Perce Lane

P.O. Box 311

Kamiah, ID 83536

J. E. Till

Route 2 Box 122

Neeses, SC 29107

D. E. Walker, Jr.

P.O. Box 4147

Boulder, CO 80306

Other

2 DOE Office of Scientific and

Technical Information

Technical Information Center

P.O. Box 62

Oak Ridge, TN 37830

B. G. Brooks, EH-421

Room J-11?

Department of Energy

Germantown, MD 20545

18 K. CharLee

Office of Nuclear Waste Mgmt.

Department of Ecology

719 Sleater Kinney Road, S.E.

Suite 200

Olympia, WA 98504

M. R. Donnelly

Public Health Service

Centers for Disease Control and Prevention

2201 Sixth Avenue, RX-22

Seattle, WA 98121
No. of

Copies

H. A. Haerer

Golder Associates, Inc.

4104 148th N.E.

Redmond, WA 98052

L. E. Denham

Centers for Disease Control and Prevention 4770 Buford Highway N.E., F-35

Atlanta, GA 30341-3724

J. P. Thomas

HEAL

1720 N. Ash

Spokane, WA 99205

\section{ONSITE}

\section{DOE Richland Operations Office}

R. F. Brich, TSD

A5-55

Public Reading Room (5)

42 Battelle, Pacific Northwest

Laboratories

D. M. Anderson

K6-57

G. L. Black (5)

K1-25

S. D. Cannon

K1-25

D. H. Denham

K3-56

D. E. Deonigi

K6-54

P. W. Eslinger

K6-96

W. T. Farris

K3-54

N. D. Foote

K7-70

M. D. Freshley

R. O. Gilbert

K6-77

K7-34

W. A. Glass (3)

K4-13

R. H. Gray

Distr. 2 
No. of

Copies

S. P. Gydesen

G. L. Harvey

C. M. Heeb

T. A. Ikenberry

B. A. Napier

J. V. Ramsdell (5)

J. A. Shaw

D. B. Shipler

J. C. Simpson
No. of

Copies

P8-55

K1-77

K6-42

K3-54

K3-54

K6-03

K1-25

K1-25

K7-34
E. D. Skyllingstad

S. A. Stage

C. D. Taylor

W. L. Templeton

M. E. Thiede

W. H. Walters

Publishing Coordination

Records Center (2)

Technical Library (2)
SEQUI

K6-03

B1-40

K1-30

K6-13

K6-09

K1-06

K3-70

P8-55

Distr. 3 

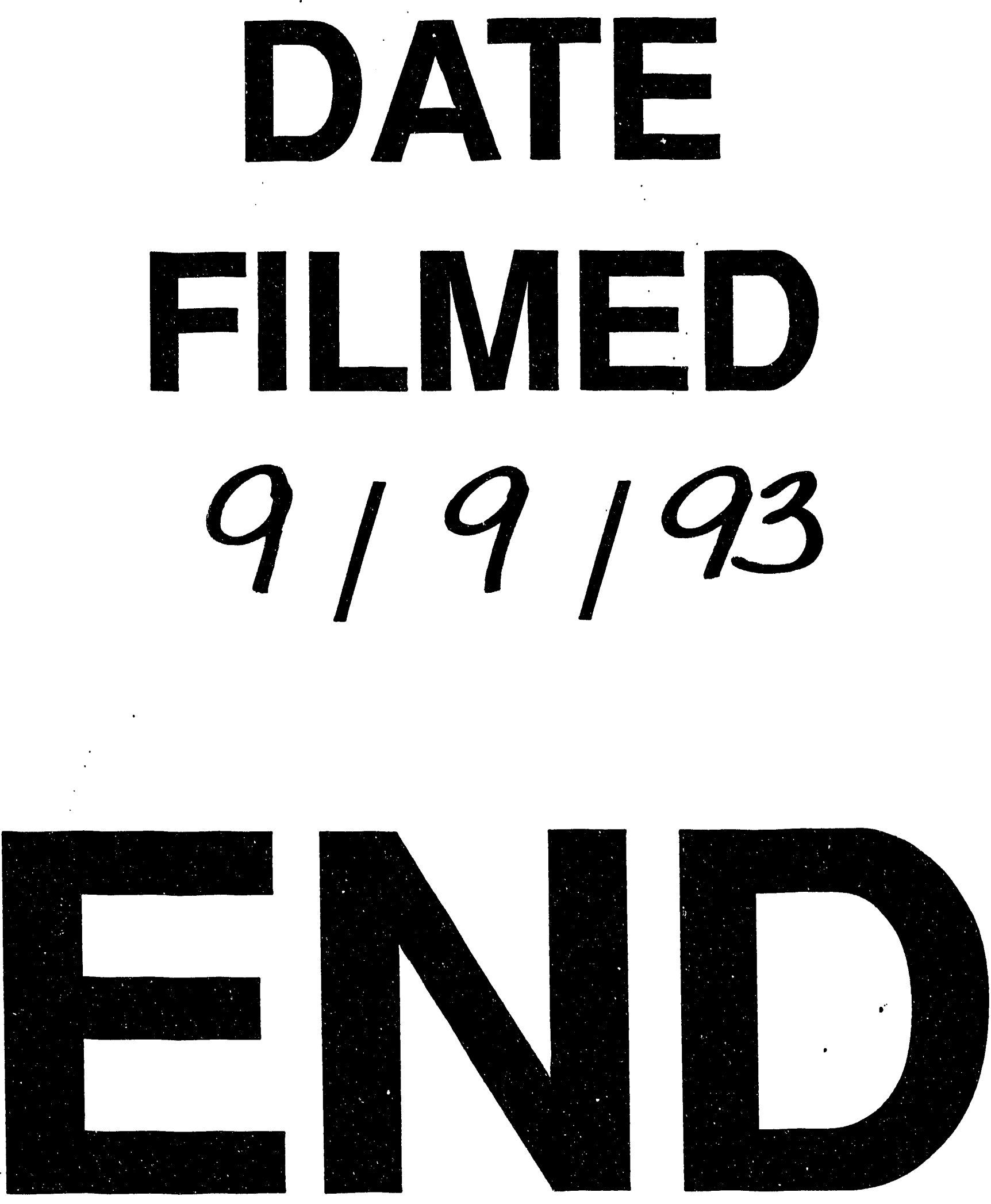
